\title{
Genetic interactions among floral homeotic genes of Arabidopsis
}

\author{
JOHN L. BOWMAN, DAVID R. SMYTH* and ELLIOT M. MEYEROWITZ† \\ Division of Bıology 156-29, Callfornua Instutute of Technology, Pasadena, Callfornia 91125, USA \\ * Permanent address. Department of Genetıcs and Developmental Bıology, Monash Unıversity, Clayton, Victona 3168, Australıa \\ $\dagger$ Author for correspondence
}

\section{Summary}

We describe allelic series for three loci, mutations in which result in homeotic conversions in two adjacent whorls in the Arabidopsis thaliana flower. Both the structure of the mature flower and its development from the initial primordium are described by scanning electron microscopy. New mutations at the APETALA2 locus, ap2-2, ap2-8 and ap2-9, cause homeotic conversions in the outer two whorls: sepals to carpels (or leaves) and petals to stamens. Two new mutations of PISTIL$L A T A$, $p i-2$ and $p i-3$, cause second and third whorl organs to differentiate incorrectly. Homeotic conversions are petals to sepals and stamens to carpels, a pattern similar to that previously described for the apetala3-1 mutation. The AGAMOUS mutations, ag-2 and $a g-3$, affect the third and fourth whorls and cause petals to develop instead of stamens and another flower to arise in place of the gynoecium. In addition to homeotic changes, mutations at the APETALA2, APETALA3 and PISTILLATA loci may lead to reduced numbers of organs, or even their absence, in specific whorls. The bud and flower phenotypes of doubly and triply mutant strains, constructed with these and previously described alleles, are also described. Based on these results, a model is proposed that suggests that the products of these homeotic genes are each active in fields occupying two adjacent whorls, $A P 2$ in the two outer whorls, $P I$ and $A P 3$ in whorls two and three, and $A G$ in the two inner whorls. In combination, therefore, the gene products in these three concentric, overlapping fields specify the four types of organs in the wild-type flower. Further, the phenotypes of multiple mutant lines indicate that the wild-type products of the AGAMOUS and $A P E T A L A 2$ genes interact antagonistically. $A P 2$ seems to keep the $A G$ gene inactive in the two outer whorls while the converse is likely in the two inner whorls. This field model successfully predicts the phenotypes of all the singly, doubly and triply mutant flowers described.

Key words: flower development, Arabıdopsts, homeotic genes.

\section{Introduction}

Flowers of Arabidopsis thaliana originate as small outgrowths of cells on the flanks of the florally induced shoot apical meristem. These cells divide and differentiate, eventually producing a flower with a precisely defined pattern of four types of floral organs, with each type found in one of the four concentric whorls of the wild-type flower (Bowman et al. 1989; Smyth et al. 1990). During the developmental process, the cells in each flower primordium must in some way assess their positions, either globally or in reference to nearby cells, and they or their descendents must subsequently differentiate to the appropriate cell types. As an approach to finding the molecular mechanisms by which cells in developing flowers recognize and realize their fates, we study genes whose products are necessary for proper pattern formation in Arabidopsis flowers.

Several such genes have been described (Pruitt $e t$ al. 1987; Meyerowitz, 1987; Bowman et al. 1988, 1989;
Komaki et al. 1988; Haughn and Somerville, 1988; Hill and Lord, 1989; Meyerowitz et al. 1989; Kunst et al. 1989; Yanofsky et al. 1990). The best-studied of them are a group of four genes whose mutant phenotypes include homeotic conversions of floral organs. These are the $A G A M O U S$ ( $A G$ ) gene, mutants of which have petals where stamens are found in wild type (the third whorl), and internal flowers in the place of the ovary (the fourth whorl in wild type); the APETALA2 (AP2) gene, different mutant alleles of which cause different conversions in the outer two of the four whorls of the flower; and the APETALA3 (AP3) and PISTILLATA $(P I)$ genes. Mutations in the $A P 3$ and $P I$ genes cause sepals to develop in the positions occupied by petals in wild-type flowers (the second whorl), and have variable effects in the third (in wild type, stamen) whorl. To date, there are published descriptions of two mutant ag alleles, ag-1 (Pruitt et al. 1987; Bowman et al. 1988, 1989) and ag-2 (Yanofsky et al. 1990), seven mutant ap2 alleles that show a broad range of related phenotypes 
(ap2-1 through ap2-7: Pruitt et al. 1987; Bowman et al. 1988, 1989; Komaki et al. 1988; Meyerowitz et al. 1989; Kunst et al. 1989), and one mutant allele each of ap3 (Bowman et al. 1989) and pi (Bowman et al. 1989; Hill and Lord, 1989).

Given the range of phenotypes seen in ap 2 mutants, in which first whorl organs can be leaves or carpels, second whorl organs petaloid stamens, stamens, or absent, and third whorl organs normal or absent, it seemed worthwhile to extend the allelic series for each of the homeotic loci. In this paper, we report the phenotypes of one new ag allele, three alleles of $a p 2$, each with phenotypes different from those described before; and two new alleles of $p i$. We also describe the mature phenotype and early development of a range of doubly and triply mutant combinations made with these new and previously described alleles.

These new data, along with those already published, have led us to a general and testable model of organ specification in Arabidopsis flowers. This model details the roles of the wild-type products of each of the homeotic genes in specifying organ identity in different regions of the developing flower. These data also provide new information on the roles of the wild-type products of the homeotic genes in establishing organ number and pattern in the flower.

\section{Materlals and methods}

The mutant alleles studied are listed in Table 1. All are recessive. The new mutations are in the Landsberg ecotype, homozygous for the erecta mutation, and were generated by mutagenesis of seeds with ethylmethane sulfonate (EMS). ag$1, a p 2-1, p t-1$, and ap3-1 were obtained from Maarten Koornneef (Department of Genetics, Wageningen Agncultural University, The Netherlands) Wild-type alleles are symbolized in block capitals and italics; mutant alleles in lower case italıcs. Individual mutant alleles are designated by a number that follows the mutant symbol and a hyphen. Doubly and triply mutant strains were constructed by manual cross-pollınation, using as parents strains homozygous for individual mutations, except in the strains involving agamous

Table 1. Description of mutants studied

\begin{tabular}{lcl}
\hline Gene & Mutant allele & \multicolumn{1}{c}{ Reference } \\
\hline AGAMOUS & $a g-1$ & Bowman et al. 1989 \\
& Yg-2 & $\begin{array}{l}\text { Yanofsky } \text { et al. 1990 } \\
\text { Present study }\end{array}$ \\
aPETALA2 & $a p 2-1$ & Bowman et al. 1989, \\
& Kunst et al 1989 \\
& $a p 2-2$ & Meyerowitz et al 1989 \\
& $a p 2-8$ & Present study \\
PISTILLATA & $a p 2-9$ & Present study \\
& $p l-1$ & Bowman et al. 1989, \\
& $p l-2$ & Hill and Lord, 1989 \\
& $p l-3$ & Present study \\
APETALA3 & $a p 3-1$ & Present study \\
& & Bowman et al. 1989
\end{tabular}

All mutations were induced in the Landsberg erecta background except for $a g-2$ which resulted from a T-DNA insertion in the Wassilewskıja ecotype alleles, which are sterile when homozygous, thus necessitating the use of heterozygotes as parents. The resulting $F_{1}$ plants were allowed to self-pollinate, and double and triple mutants were selected from the $F_{2}$ plants. Seeds were planted on a peat moss/potting soil/sand (3:3:1, v:v:v) mixture. The plants were grown in incubators under constant cool-white fluorescent light at $25^{\circ} \mathrm{C}$ (unless otherwise stated) and $70 \%$ relative humidity.

For scanning electron microscopy (SEM), young primary inflorescences were fixed in $4 \%$ glutaraldehyde in $0.025 \mathrm{M}$ sodium phosphate $(\mathrm{pH} 70)$ at $4^{\circ} \mathrm{C}$ overnight, and then transferred to $1 \%$ osmium tetroxide in the same buffer at $4^{\circ} \mathrm{C}$ overnight. They were rinsed in the same buffer and dehydrated in a graded ethanol series at $4^{\circ} \mathrm{C}$. This material was critical point dried in liquid carbon dioxide. Individual flowers were removed from inflorescences and mounted on SEM stubs. Organs were dissected from individual flowers using glass needles The mounted specimens were coated with gold and palladium (4:1) in a Technics Hummer V sputter coater following each dissection. SEM was performed on an ETEC Autoscan scanning electron microscope at an accelerating voltage of $20 \mathrm{kV}$, and the images recorded on Kodak 4127 or Polaroid 55 film

\section{Results}

\section{Wild type}

Wild-type Arabidopsis thaliana flowers (Fig. 1A) contain four concentric regions (whorls), each occupied by a different organ type (Bowman et al. 1989). The first (outermost) whorl of the wild-type flower contains four sepals, two medial and two lateral (with respect to the stem of the inflorescence). The second whorl holds four petals, which are in alternate positions with the sepals. The third whorl includes six stamens, four long medial ones and two short lateral. The fourth whorl is occupied by the gynoecium, which consists of a two-chambered ovary topped with a short style, and capped with a stigma. Nectaries, which appear as small cellular mounds with stomata on top, are formed at the base of the stamens, though their presence is variable, so that in any flower some stamens may have them, and others may not. The individual cells that constitute each organ are characteristic of the organ type, so that both overall structure and cellular identity can be used as criteria for organ type.

The development of the flowers has been described in detail, and divided into twelve stages from the first appearance of a flower primordium, to anthesis (Müller, 1961; Bowman et al. 1989; Hill and Lord, 1989; Smyth et al. 1990; Fig. 2A). New flower primordia are added at the top of the inflorescence, where the growing point is, in a spiral phyllotactic pattern. The inflorescence is thus a raceme, and an individual inflorescence may contain a complete developmental series of flowers, from the youngest primordium at the apex, to mature fruits toward the base.

\section{Single mutant strains}

agamous

Two agamous alleles have been described previously, ag-1 (Bowman et al. 1989) and ag-2 (Fig. 1B, Yanofsky 
et al. 1990) and we report here the isolation of a third allele, $a g-3$ (Table 1) The $a g-1$ and $a g-3$ mutants have very similar phenotypes; the ag-2 mutant has a somewhat different appearance. In all the mutants, whorls one and two appear normal, while in whorl three the positions occupied by the six stamens in wild type are occupied by six petals, and in whorl four the cells where the gynoecium normally develops differentiate into a new flower, consisting generally of an outer whorl of sepals, and two whorls of petals. Since this process of formation of flowers within flowers contınues, mutant flowers can consist of at least five nested flowers, with a total of 70 or more organs (Bowman et al. 1989). All of the mutants also show a less than perfect repetition in the inner flowers. Some inner flowers have fewer than 10 petals, and some of the organs may arise in ectopic positions. The internal sepalloid organs are often not perfect sepals, but can be mosaics of petal and sepal tissue, with the petal tissue always forming in longitudinal sectors on the outer margins of the organs. Development of $a g-2$ flowers resembles that of $a g-1$ flowers (Bowman et al. 1989), as can be seen in Fig. 2B. The one difference so far observed is that ag-2 homozygous flowers show a greater degree of pedicel elongation of the internal flowers than ag- 1 and ag-3. Very likely this is due to a difference at the erecta locus, which when mutant reduces internode elongation throughout the plant. The $a g-1$ and $a g-3$ mutants are in the erecta background; $a g-2$ is not (Table 1 ). None of these ag alleles is temperature sensitive.

apetala2

Detailed descriptions are available for ap2-1 (Bowman et al. 1989) and ap2-5, -6, and -7 (Kunst et al. 1989), and briefer descriptions of ap2-2 (Meyerowitz et al. 1989) and $a p$ 2-3 and -4 (Komaki et al. 1988) have also been published. We give here a detailed description of the flowers and of their development in homozygotes for three further alleles, ap2-2, ap2-8, and ap2-9 (Table 1). All of these show a greater departure from wild type than any of the mutants previously described. These descriptions extend the allelic series, and indicate new functions for the wild-type $A P 2$ gene product. In addition, we found that the three alleles are all temperature-sensitive, as has been previously shown for ap2-1 (Bowman et al. 1989), implying that the underlying process or the wild-type protein, rather than the mutant gene product specifically, is affected by temperature changes.

apetala2-2

The most extreme allele characterized to date is ap2-2. Flowers of plants homozygous for this allele consist mostly of carpelloid and staminoid organs (Fig. 1C, Tables 2-4). The identities of the outer two whorls of organs are altered and, in addition, the numbers and/or positions of organs in all four whorls may be altered. Phenotypic differences are observed between the lateral and medial first whorl organ positions and thus they are treated separately (Table 2). About half of the time, the lateral positions have no organ development. When organs do form they tend to be cauline leaf-like organs with stellate trichomes on their abaxial surfaces and stipules at their bases (both characteristics of leaf development) or carpelloid leaf-like organs with stigmatic tissue at their tips and rudimentary ovules along their margins (Table 2). Each of these organs may have the long abaxial epidermal cells characteristic of sepals. The lateral first whorl positions can also be occupied by filamentous structures, some of which have leaf-like

Table 2. Percentage of organs of various types in the first whorl positions of ap2 mutants

\begin{tabular}{|c|c|c|c|c|c|c|c|}
\hline \multirow[b]{2}{*}{ Organ } & \multicolumn{7}{|c|}{ Genotype (No of flowers scored) } \\
\hline & $\begin{array}{c}a p 2-2 \\
(39)\end{array}$ & $\begin{array}{l}a p 2-8 \\
(24)\end{array}$ & $\begin{array}{c}a p 2-9 \\
(48)\end{array}$ & $\begin{array}{c}a p 2 \cdot 1 / a p 2 \cdot 2 \\
(36)\end{array}$ & $\begin{array}{c}a p 2-1 / a p 2-9 \\
(26)\end{array}$ & $\begin{array}{c}a p 2-1^{*} \\
(41)\end{array}$ & $\begin{array}{l}\text { wild type } \\
\text { (47) }\end{array}$ \\
\hline \multicolumn{8}{|c|}{ A Medial first whorl positions } \\
\hline sepals & $0 \%$ & $0 \%$ & $0 \%$ & $0 \%$ & $0 \%$ & $0 \%$ & $100 \%$ \\
\hline leaves & $0 \%$ & $0 \%$ & $0 \%$ & $14 \%$ & $19 \%$ & $100 \%$ & $0 \%$ \\
\hline carpelloid leaves & $0 \%$ & $2 \%$ & $5 \%$ & $32 \%$ & $50 \%$ & $0 \%$ & $0 \%$ \\
\hline staminoid carpels & $37 \%$ & $60 \%$ & $40 \%$ & $0 \%$ & $0 \%$ & $0 \%$ & $0 \%$ \\
\hline carpels & $63 \%$ & $35 \%$ & $45 \%$ & $54 \%$ & $31 \%$ & $0 \%$ & $0 \%$ \\
\hline absent & $0 \%$ & $0 \%$ & $0 \%$ & $0 \%$ & $0 \%$ & $0 \%$ & $0 \%$ \\
\hline other & $0 \%$ & $2 \%$ & $9 \%$ & $0 \%$ & $0 \%$ & $0 \%$ & $0 \%$ \\
\hline \multicolumn{8}{|c|}{ B. Lateral first whorl positions } \\
\hline sepals & $0 \%$ & $0 \%$ & $0 \%$ & $0 \%$ & $0 \%$ & $0 \%$ & $100 \%$ \\
\hline leaves & $32 \%$ & $10 \%$ & $13 \%$ & $93 \%$ & $96 \%$ & $100 \%$ & $0 \%$ \\
\hline carpelloid leaves & $17 \%$ & $23 \%$ & $2 \%$ & $0 \%$ & $2 \%$ & $0 \%$ & $0 \%$ \\
\hline staminoid carpels & $0 \%$ & $0 \%$ & $0 \%$ & $0 \%$ & $0 \%$ & $0 \%$ & $0 \%$ \\
\hline carpels & $0 \%$ & $0 \%$ & $0 \%$ & $0 \%$ & $0 \%$ & $0 \%$ & $0 \%$ \\
\hline absent & $44 \%$ & $56 \%$ & $76 \%$ & $6 \%$ & $2 \%$ & $0 \%$ & $0 \%$ \\
\hline other & $7 \%$ & $10 \%$ & $9 \%$ & $1 \%$ & $0 \%$ & $0 \%$ & $0 \%$ \\
\hline
\end{tabular}

Flowers scored were the first $10-15$ produced on the primary inflorescence of plants raised at $25^{\circ} \mathrm{C}$ In the medial positions, the organs in the 'other' category usually had charactenstics of leaves, carpels and stamens, organs in the lateral positions classified as 'other' were usually filamentous structures, either thin leaf-like structures with occasional stellate tnchomes or much thinner squamule-like structures (for example, see Fig 4C)

* from Bowman et al. 1989, ** from Smyth et al 1990 

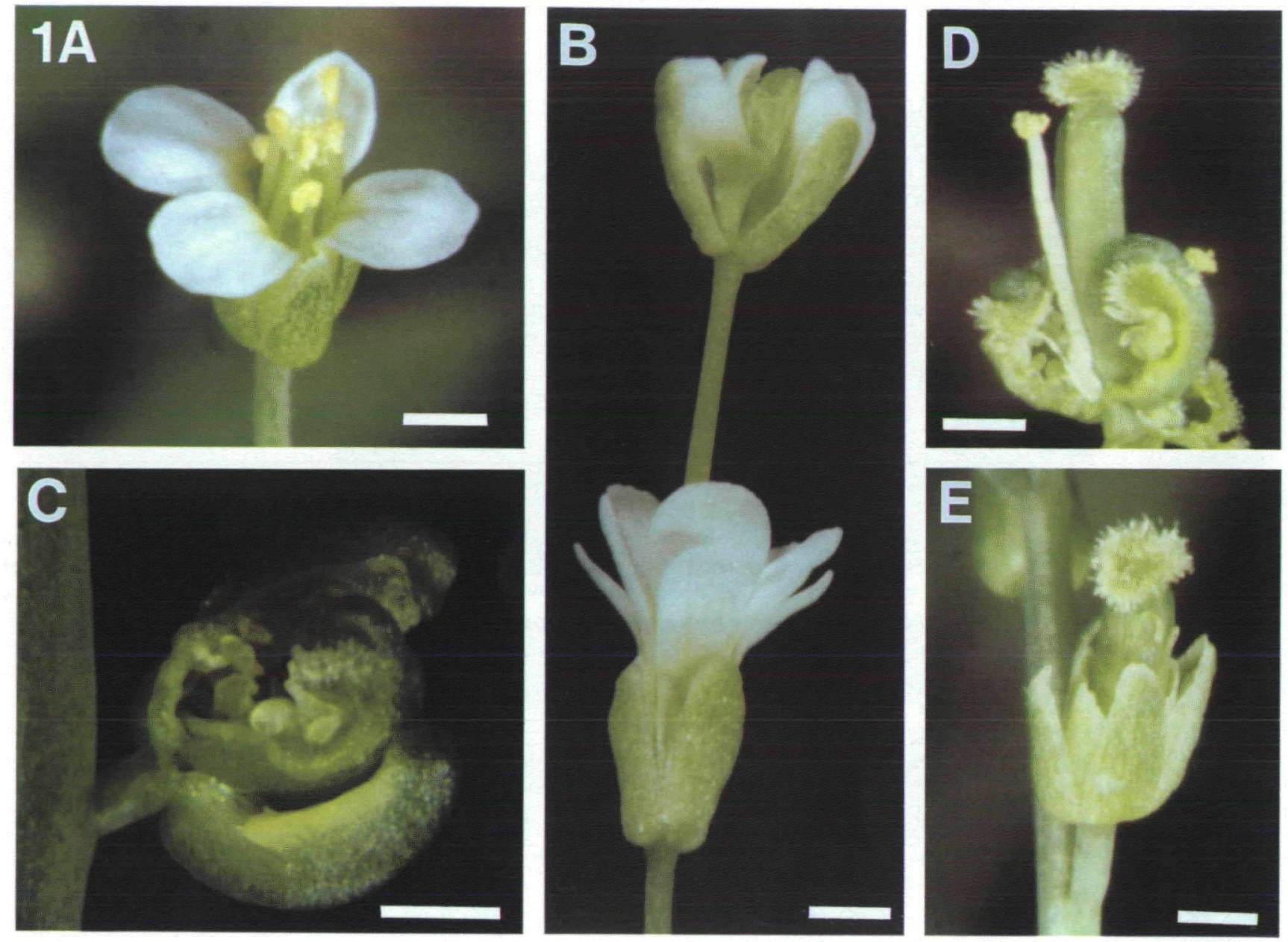

Fig. 1. Phenotypes of wild-type and mutant Arabidopsus flowers. (A) wild type (B) agamous-2 (C) apetala2-2 (D) apetala2-9 (E) pistullata-1/pistillata-2. The plants were grown at $25^{\circ} \mathrm{C}$. Bar $=1 \mathrm{~mm}$. 


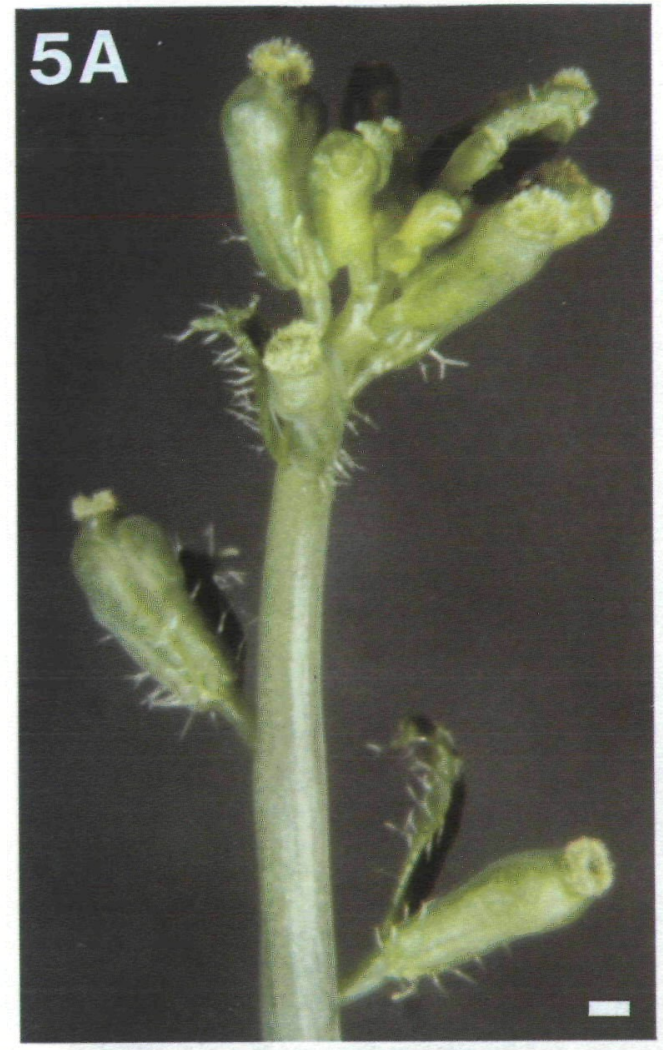

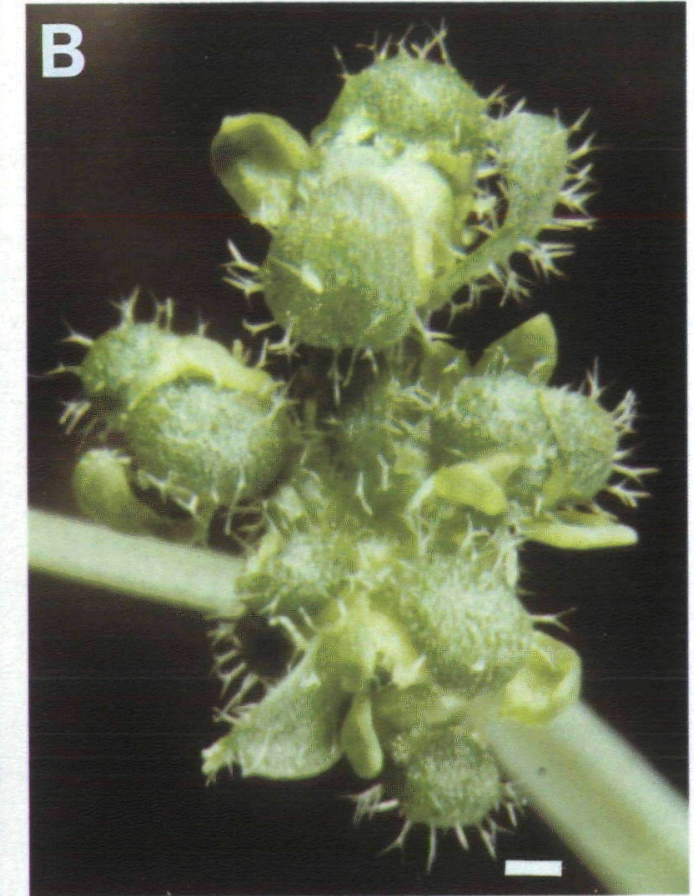

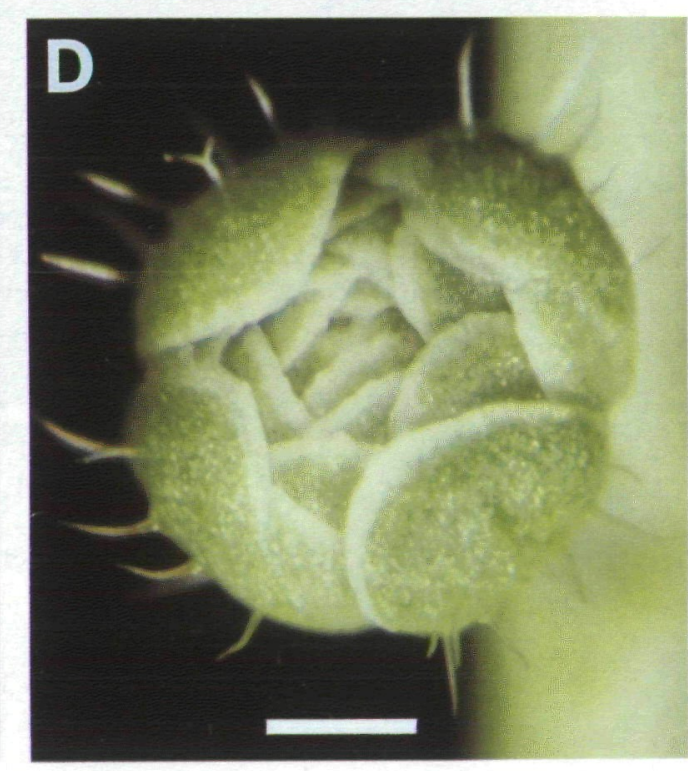

Fig. 5. Phenotypes of double mutant strains. (A) apetala2-2 pustillata-1 (B) apetala2-2 agamous-1 (C) agamous-1 pustllata-1 (D) agamous-1 apetala3-1 Plants grown at $25^{\circ} \mathrm{C} \cdot \mathrm{Bar}=1 \mathrm{~mm}$.

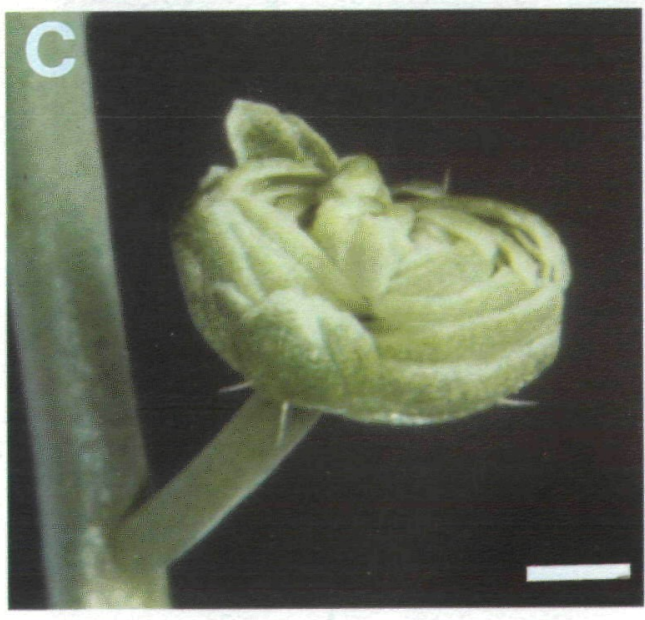

Fig. 7. Phenotypes of triply mutant flowers. (A) apetala $2-1$ agamous-1 apetala3-1 (B) apetala2-1 agamous-1 pustllata-1 (C) apetala 2-2 agamous-1 pistillata-1. All plants grown at $25^{\circ} \mathrm{C}$. Bar $=1 \mathrm{~mm}$.
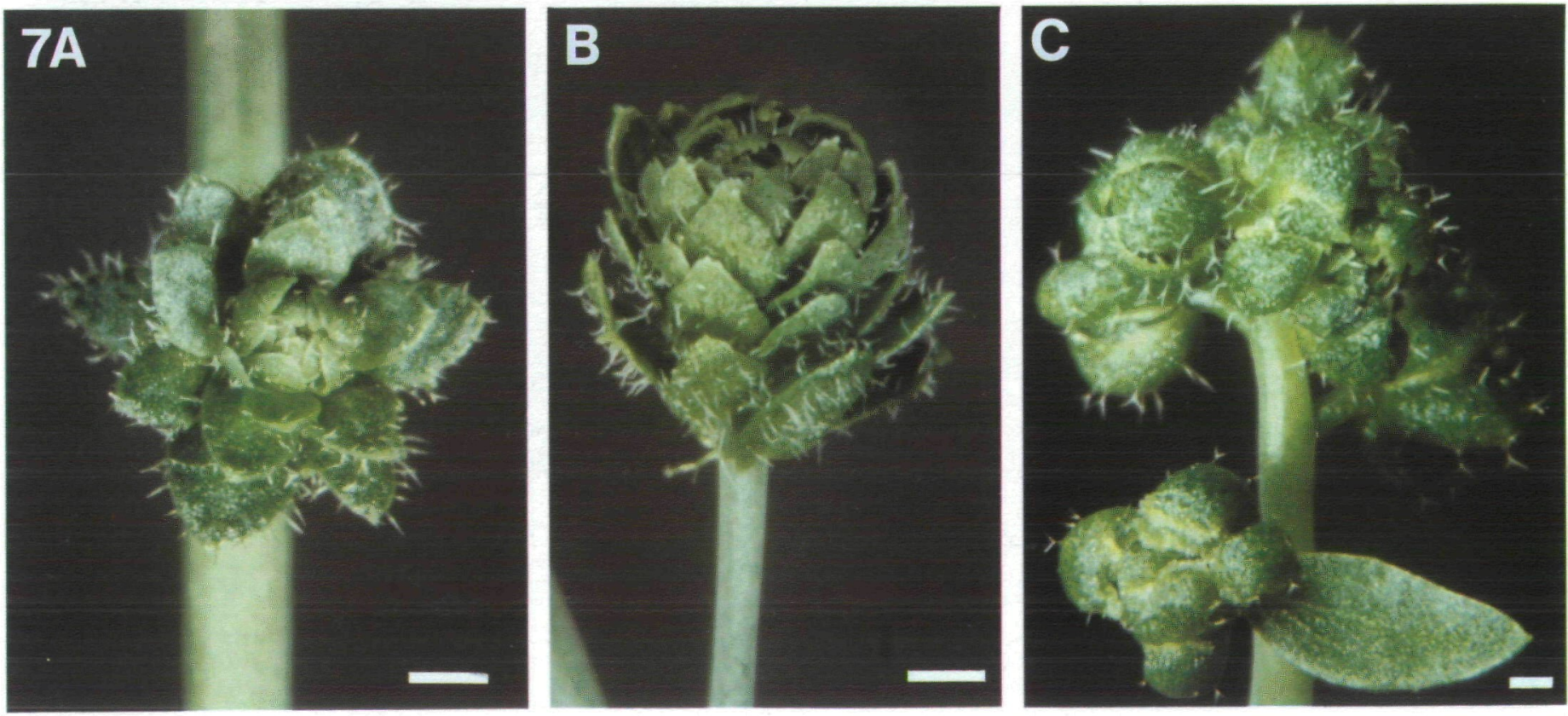

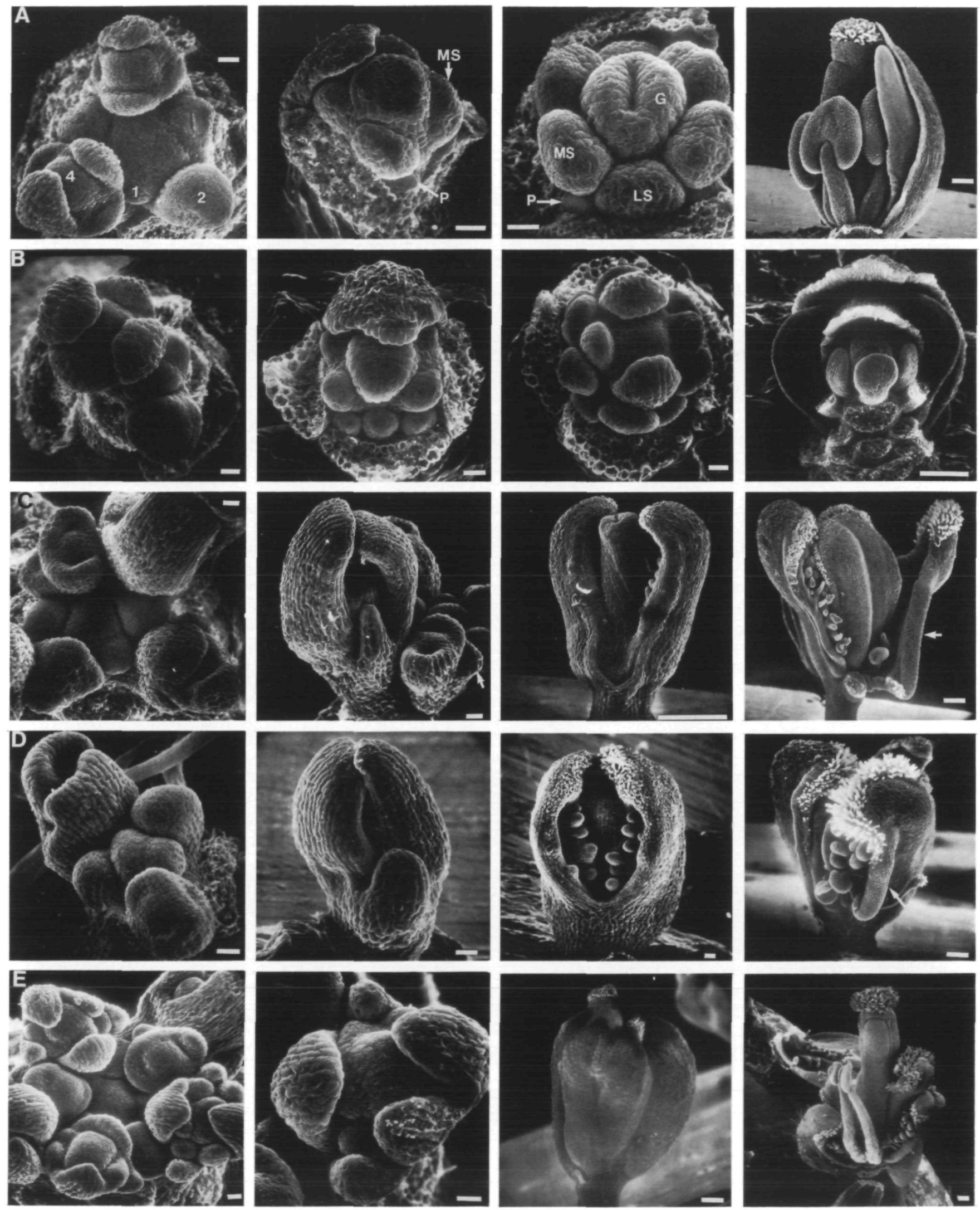

character (such as stellate trichomes) while others are squamule-like structures, thin filamentous outgrowths of cells that have been observed in other species of

Brassicaceae (Arber, 1931) and in ap1-1 flowers of Arabudopsis (Insh and Sussex, 1990; D.R.S. and J.L.B.). In contrast, the medial first whorl positions are 

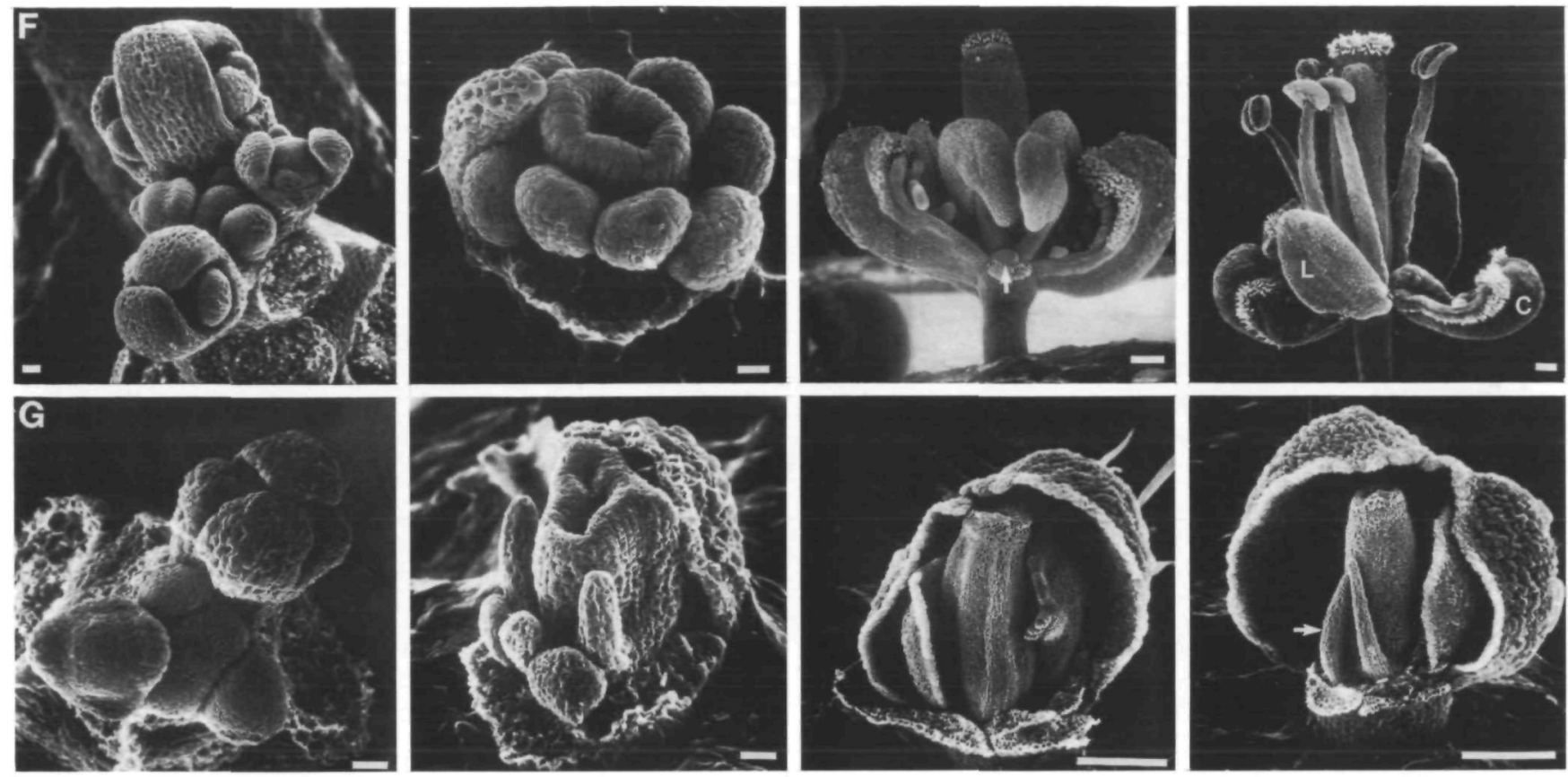

Fig. 2. Scanning electron micrographs depicting the development of wild-type and mutant Arabıdopsts flowers. The first (left) panel in each row displays the apical meristem and the early stages of flower development (stages 1 to 4 or 5). The second and third panels show successively older developing flowers, and the fourth panel shows flowers nearing maturity. First and second whorl organs have been removed in most cases to reveal the underlyıng organs. The positions of medial and lateral are with respect to the apical (primary inflorescence) meristem. Growth conditions for each were $25^{\circ} \mathrm{C}$ and $24 \mathrm{~h}$ illumination except $\mathrm{E}$ which was $16^{\circ} \mathrm{C}$. Bar $=10 \mu \mathrm{m}$ in the first two panels; $10 \mu \mathrm{m}$ in the third panels of $\mathrm{A}, \mathrm{B}$ and $\mathrm{D}, 100 \mu \mathrm{m}$ in the third panels of $C, E, F$ and $G ; 50 \mu \mathrm{m}$ in the fourth panel of $B$ and $100 \mu \mathrm{m}$ in the remaining fourth panels. (A) Wild type In the first panel, the stage of some of the individual flower pnmordia is indicated. Petal (P) and medial stamen (MS) primordia are indicated on the stage six flower in the second panel. One lateral stamen primordium is not present, as often seen in wild-type flowers (Muller, 1961, Smyth et al. 1990). Petal (P), medial stamen (MS), lateral stamen (LS), and the gynoecial $(G)$ primordia are indicated on the stage 7 flower in the third panel. The fourth panel shows a stage 12 flower (3 sepals and 2 petals have been removed) in which the cell types of each of the four floral organs are visible. (B) agamous-2. Note the internal flowers in panels three and four. First whorl organs have been removed in the second and third panels and organs in the first four whorls were removed from the flower in the fourth panel. (C) apetala2-2 Medial first whorl organ primordia are enlarged relatıve to wild type (first panel). A lateral first whorl primordium (arrow) is indicated in the second panel; its position is lower on the pedicel than is seen in wild type (A) The central gynoecium of ap2-2 flowers is often twisted (third panel) and usually fauls to develop normally (fourth panel). A stamen-carpel mosaic in a medial first whorl position is indicated in the fourth panel (arrow). (D) apetala2-8. The two medial first whorl organs are enlarged relative to wild type (first panel) and develop into solitary carpels with promınent ovules and stıgmatıc tissue (third panel) or develop into carpel-stamen mosaic organs (arrow in fourth panel) (E) apetala2-9. Organ primordia of ap2-9 flowers grown at $16^{\circ} \mathrm{C}$ do not appear in the normal number or position, as seen in the second panel The outer whorl organ primordia may congenitally fuse to form a ring-like structure as shown in the third panel. (F) apetala2-1/apetala2-2. When fewer than the normal number of organ primordia form in the second and third whorls, those that do anise occur in ectopic positions as seen in the second panel. The lack of organs in most second whorl positions is due to the failure to form organ primordia (second panel). A nectary is noted in the third panel (arrow) in the normal lateral position; the lateral first whorl organ has been removed. Note the different phenotypes of the first whorl organs of the flower in panel four; the lateral ones are leaf-like (L) while the medial ones are solitary carpels $(\mathrm{C})$. (G) pistllata-2. Some third whorl organ primordia are apparently congenitally fused to the developing gynoecial cylinder, as seen in the second panel When the thurd whorl organ primordia are free, they often develop into filamentous structures, indicated in the fourth panel (arrow) Second whorl sepals are visible in the third and fourth panels.

always occupied and exhibit a greater degree of carpellody. Solitary carpels capped with stigmatic tissue, and exhibiting marginal ovules are the most common organ in these positions (Table 2). Scanning electron microscope analysis of the epidermal cells of these organs shows cellular morphologies ranging from carpel-like (with a lower ovary-like portion of regular cellular files, and an upper stylar portion) to cauline leaf-like (consisting of irregularly shaped cells with occasional stellate trichomes). On occasions, these carpelloid medial first whorl organs are fused to the central, fourth whorl gynoecium. In many cases, the medial first whorl organs are mixtures of stamen and carpel tissue (Table 2, Figs $1 \mathrm{C}, 2 \mathrm{C}$ ). The staminal portion is always positioned at the outer margins of the organs, while the carpelloid tissue is central. The stamen sectors have both epidermal and internal cellular morphologies resembling those of wild-type 
Table 3. Percentage of organs of various types in the second whorl positions of ap 2 mutants

\begin{tabular}{|c|c|c|c|c|c|c|c|}
\hline \multirow[b]{2}{*}{ Organ } & \multicolumn{7}{|c|}{ Genotype (No. of flowers scored) } \\
\hline & $\begin{array}{l}a p 2-2 \\
(39)\end{array}$ & $\begin{array}{l}a p 2-8 \\
(24)\end{array}$ & $\begin{array}{c}\operatorname{ap} 2-9 \\
(48)\end{array}$ & $\begin{array}{c}a p^{2-1 / a p 2-2} \\
\text { (36) }\end{array}$ & $\begin{array}{c}a p 2-1 / a p 2-9 \\
\text { (26) }\end{array}$ & $\begin{array}{c}a p 2-l^{*} \\
(41)\end{array}$ & $\begin{array}{l}\text { wild type** } \\
\text { (47) }\end{array}$ \\
\hline petals & $0 \%$ & $0 \%$ & $0 \%$ & $0 \%$ & $0 \%$ & $9 \%$ & $100 \%$ \\
\hline stamınord petals & $0 \%$ & $0 \%$ & $0 \%$ & $1 \%$ & $3 \%$ & $37 \%$ & $0 \%$ \\
\hline petaloıd stamens & $0 \%$ & $0 \%$ & $0 \%$ & $8 \%$ & $4 \%$ & $24 \%$ & $0 \%$ \\
\hline stamens & $0 \%$ & $0 \%$ & $0 \%$ & $4 \%$ & $24 \%$ & $2 \%$ & $0 \%$ \\
\hline absent & $100 \%$ & $100 \%$ & $100 \%$ & $87 \%$ & $69 \%$ & $29 \%$ & $0 \%$ \\
\hline
\end{tabular}

Flowers scored were the first $10-15$ produced on the primary inflorescence of plants rased at $25^{\circ} \mathrm{C}$ White petal-shaped organs possessing rudimentary locules were termed staminoid petals and organs shaped like stamens, but with some white petal tissue, usually near the tıp, were classified as petalord stamens Those organs classified as petals and stamens were morphologically wild type.

* from Bowman et al 1989; ** from Smyth et al 1990

Table 4. Percentage of organs of various dispositions in the third and fourth whorl positions of apetala2 mutants

\begin{tabular}{cccccccc}
\hline & \multicolumn{7}{c}{ Genotype (No. of flowers scored) } \\
\cline { 2 - 8 } & $\begin{array}{c}a p 2-2 \\
(39)\end{array}$ & $\begin{array}{c}a p 2-8 \\
(24)\end{array}$ & $\begin{array}{c}a p 2-9 \\
(48)\end{array}$ & $\begin{array}{c}a p 2-1 / a p 2-2 \\
(36)\end{array}$ & $\begin{array}{c}\text { ap2-1/ap2-9 } \\
(26)\end{array}$ & $\begin{array}{c}\text { ap2-1* } \\
(41)\end{array}$ & $\begin{array}{c}\text { wld type** } \\
(47)\end{array}$ \\
\hline $\begin{array}{c}\text { third whorl stamens } \\
\text { (\% present) } \\
\text { fourth whorl carpels } \\
\text { fused normally }\end{array}$ & $8 \%$ & $4 \%$ & $14 \%$ & $93 \%$ & $95 \%$ & $87 \%$ & $96 \%$ \\
& $28 \%$ & $42 \%$ & $42 \%$ & $100 \%$ & $100 \%$ & $100 \%$ & $100 \%$
\end{tabular}

Flowers scored were the first 10-15 produced on the primary inflorescence of plants raised at $25^{\circ} \mathrm{C}$.

* from Bowman et al 1989; * from Smyth et al 1990

stamens, but the central carpelloid sectors have cellular morphologies ranging from those characteristic of carpels to leaf-like. Individual, phenotypically mosaic organs of this type can contain both ovules and pollen.

There are no organs in the positions occupied by second whorl organs in wild-type flowers in ap 2-2 homozygotes (Table 3 ). This is due to a failure to form organ primordia. The third and fourth whorls are affected with respect to position and number but their identities are not altered. Third whorl positions are largely unoccupied (Table 4, Fig. 1C). When the third whorl organs are present, they are normal and fertile stamens and tend to occupy the lateral positions. Two carpels occupy the fourth whorl but they often fail to fuse properly (Table 4). In addition, when they do fuse correctly, the resulting gynoecia are usually not oriented as they would be in wild type (Fig. 2C). In 14 out of 15 fused carpel gynoecia of ap 2-2 homozygotes scored, they were either twisted, or oriented $90^{\circ}$ from the wild-type orientation. The gynoecium is nonetheless functional, setting seed when manually pollinated.

The development of ap2-2 flowers diverges morphologically from that of wild type as early as stage three, the stage when the organ primordia of the first whorl arise (Fig. 2C). This is slightly after the beginning of the temperature-sensitive period (stage two) that was determined for second whorl organ development in ap2-1 homozygotes (Bowman et al. 1989). The medial first whorl organs are enlarged relative to wild type, and grow rapidly, with the cell files typical of gynoecial development. These organs develop ovules on their margins and stigmatic papillae at their apices prior to the formation of the same features in the central gynoecium. Stipules, which are characteristic of early leaf development (Smyth et al. 1990), and which are seen at the base of developing first whorl organs of $a p 2$ 1 homozygotes (Bowman et al. 1989), are not seen in medial first whorl ap2-2 organs. Lateral first whorl primordia, when present, appear to originate lower on the pedicel of the flower primordium than organs in the same position in wild-type flowers (Fig. 2C) and the organs that develop in these positions often have stipules at their bases. The occasional stamens that are observed developing in third whorl positions occupy the lateral positions, and there are a maximum of two stamens in any developing flower. In wild type, nectaries are always associated with stamens, while in ap2-2 homozygotes nectaries can be present regardless of the occurrence of stamens. The remaining floral meristem gives rise to the gynoecial cylinder. Its growth is often irregular, and the division between the two carpels occurs in an abnormal orientation. Observations on developing mutant flowers show that the absence of organs in positions normally occupied in the second and third whorls does not result from failure of initiated organ primordia to develop, but rather results from the failure of primordia to appear in these positions. This also occurs in most of the lateral first whorl positions that lack organs; occasionally, however, a small mound of cells may occur in these positions in which no organ develops. It is unclear whether these outgrowths represent aborted organ primordia or some 


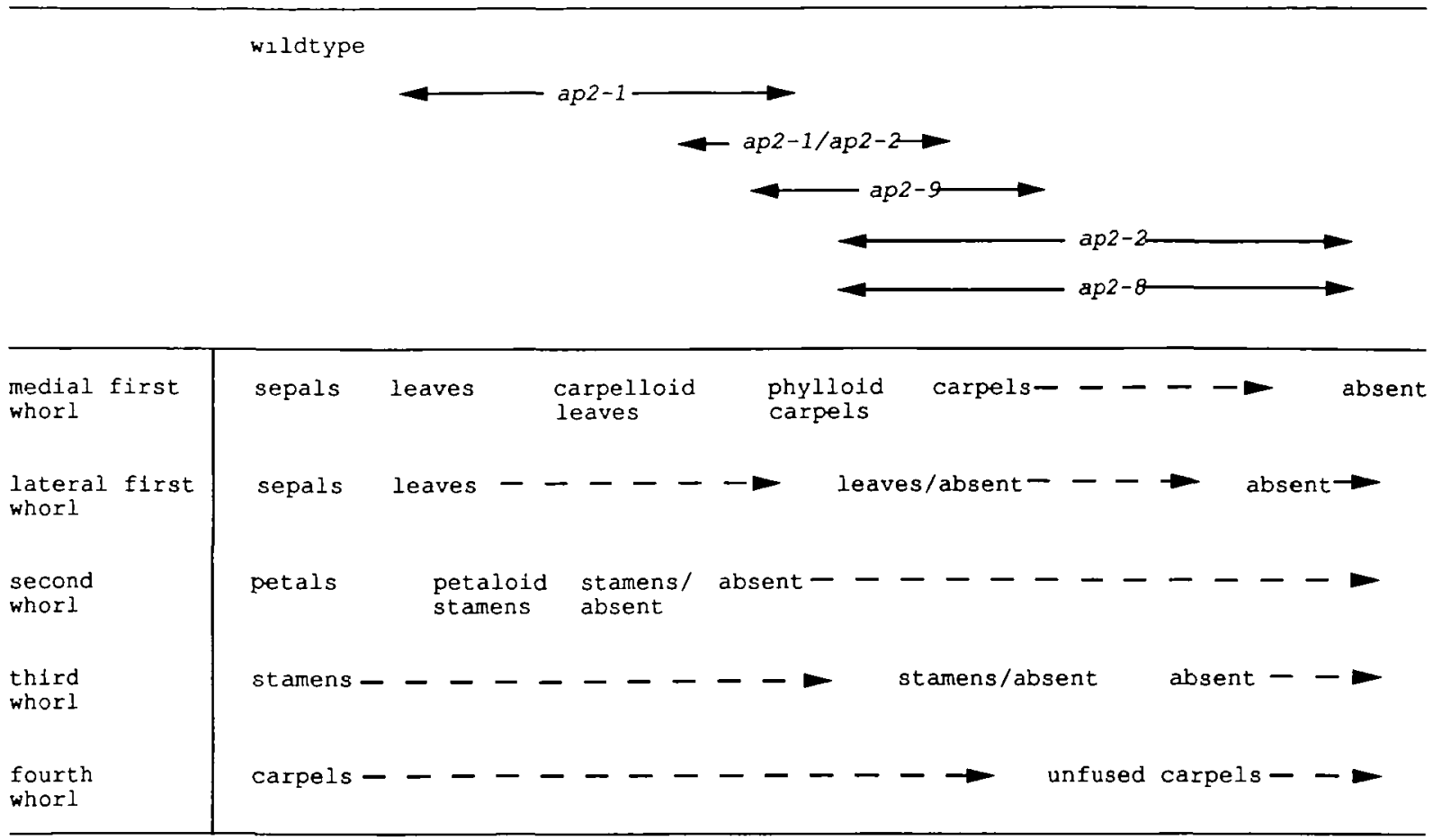

Fig. 3. The range of phenotypes of each of the described $a p 2$ alleles is displayed. The left end of the arrow for each allele represents its phenotype at $16^{\circ} \mathrm{C}$ whereas the right end represents its phenotype at $29^{\circ} \mathrm{C}$. The phenotype (medial first whorl, lateral first whorl, second whorl, third whorl, fourth whorl) for any particular allele is read from top to bottom For example, the phenotype of ap2-1/ap2-2 flowers ranges from (carpellord leaves, leaves, stamens/absent, stamens, carpels) at $16^{\circ} \mathrm{C}$ to (carpels, leaves/absent, absent, stamens/absent, carpels) at $29^{\circ} \mathrm{C}$.

other structure. Thus, in addition to changes in organ identity, mutations in the ap2 locus change basic organ number in flowers.

When ap2-2 plants are grown at low temperature $\left(16^{\circ} \mathrm{C}\right)$, the frequency of occurrence of lateral first whorl and all third whorl organs is increased compared to $25^{\circ} \mathrm{C}$. Nonetheless, second whorl organs fail to develop. In addition, the first whorl organs may fuse to each other as described below for ap 2-9 flowers grown at $16^{\circ} \mathrm{C}$. When they are grown at $29^{\circ} \mathrm{C}$, ap $2-2$ homozygotes frequently fail to produce any first, second or third whorl primordia at all. This results in flowers that contain only a gynoecium, which is typically composed of two carpels oriented at $90^{\circ}$ from the positions occupied by the two carpels in wild type.

\section{apetala2-8}

Flowers of plants homozygous for the ap2-8 allele are similar to those of ap2-2 homozygotes in both their mature phenotype (Tables 2-4) and their ontogeny (Fig. 2D). The ap2-8 homozygotes are also similar to those of ap2-2 in their response to different growth temperatures, with greater organ loss and more complete organ conversions at higher temperatures, and less departure from wild type at lower temperatures (Fig. 3).

apetala2-9

Plants homozygous for the ap2-9 mutation have flowers with a phenotype slightly closer to wild type than plants homozygous for $a p 2-2$ or ap2-8 (Fig. 1D). Briefly, the medial first whorl organs are carpellond and the lateral first whorl organs often fall to develop (Table 2). No organs form in the second whorl positions (Table 3 ) and the third whorl is also largely unoccupied (Table 4). When third whorl organs are present, they form normal fertile stamens. Two carpels occupy the fourth whorl, but they often fail to be properly fused (Table 4).

When grown at $16^{\circ} \mathrm{C}$, flowers homozygous for ap2-9 exhibit both numerical and positional abnormalities (Fig. 2E). Although fewer organs are missing than in flowers grown at higher temperatures, those organs that are present tend to occupy ectopic positions and are often fused to each other. For example, lateral first whorl primordia are frequently present, though they appear to arise lower on the pedicel of the developing flower than do lateral first whorl organ primordia in wild type. These organ primordia differentiate to become carpelloid leaves, which are often fused to the more-carpelloid medial first whorl organs to form a connate ring, with marginal ovules and stigmatic tissue at its top (Fig. 2E). Sometimes a fifth organ primordium arises between the positions ordinarily occupied by first and second whorl organs (Fig. 2E). Second whorl organs appear to be absent, though there are stamens, carpelloid stamens and solitary carpels whose positions do not allow their assignment to the second or third whorl. Third whorl organs, which also arise in ectopic positions, are normal stamens, and the ovary is usually normal. 
Table 5. Percentage of organs of various types in the six third whorl posinons of pistillata and apetala3 mutants

\begin{tabular}{|c|c|c|c|c|c|c|}
\hline \multirow[b]{2}{*}{ Organ } & \multicolumn{6}{|c|}{ Genotype (No of flowers scored) } \\
\hline & $\begin{array}{l}p_{l-1}{ }^{*} \\
(75)\end{array}$ & $\begin{array}{c}p l-1 / p l-2 \\
(40)\end{array}$ & $\begin{array}{l}p l-2 \\
\text { (15) }\end{array}$ & $\begin{array}{l}p l-3 \\
(27)\end{array}$ & $\begin{array}{l}a p 3-1^{*} \\
(15)\end{array}$ & $\begin{array}{l}\text { wlld-type } \\
\text { (47) }\end{array}$ \\
\hline $\begin{array}{l}\text { stamens } \\
\text { filamentous structures } \\
\text { carpellord organs } \\
\text { absent }\end{array}$ & $\begin{array}{r}0 \% \\
14 \% \\
0 \% \\
86 \%\end{array}$ & $\begin{array}{r}0 \% \\
83 \% \\
5 \% \\
12 \%\end{array}$ & $\begin{array}{r}0 \% \\
54 \% \\
12 \% \\
33 \%\end{array}$ & $\begin{array}{r}0 \% \\
17 \% \\
66 \% \\
17 \%\end{array}$ & $\begin{array}{l}29 \% \\
<1 \% \\
53 \% \\
18 \%\end{array}$ & $\begin{array}{r}96 \% \\
0 \% \\
0 \% \\
4 \%\end{array}$ \\
\hline
\end{tabular}

Flowers scored were the first $10-15$ produced on the primary inflorescence of plants raised at $25^{\circ} \mathrm{C}$. In the case of the $p \imath$ mutants, many of the organs were fused with the central gynoecium The apparent absence of many third whorl organs in the strongest allele, pi-1, may reflect their complete incorporation into the fourth whorl gynoectum

* from Bowman et al. 1989; ** from Smyth et al 1990

\section{trans-heterozygotes}

In addition to characterizing the phenotype of homozygotes of each of the three extreme $a p 2$ alleles, we have made all possible heterozygous combinations of these alleles with each other, and with ap 2-1, the allele whose homozygotes show the least departure from wild type (at $259 \mathrm{C}$, four first whorl leaves, four second whorl petalloid stamens, normal third and fourth whorls). In each case, the phenotype of the heterozygotes is intermediate between that of the homozygotes for each allele involved. ap2-1/ap2-2 heterozygotes (Fig. 2F, Tables 2-4), representing a combination of the two extremes of the ap 2 allelic series, are discussed because they emphasize aspects of the ap2 phenotype, in particular the difference in phenotype between the lateral and medial first whorl organs, the failure of organ primordium formation in the second and third whorls, and the abnormal positions of the remaining second and third whorl organ primordia. ap2-1/ap2-2 flowers have lateral first whorl organs that resemble cauline leaves, usually ( $76 \%$ of 72 organs scored) with stigmatic tissue at their tips, whereas the medial first whorl organs are much more carpelloid (Table 2, Fig. 2F). These positions are occupied by solitary carpels or carpelloid leaves, with ovules at their margins in addition to stigmatic papillae at their tips. The carpellody of the first whorl organs increases with the age of the inflorescence, with the cauline leaf-like organs present only on the first few flowers, and the solitary carpels generally present in later flowers. This trend has been observed for all the ap2 alleles. Second whorl organs are usually absent and their absence is due to the fallure of organ primordia to form, not to failure of initiated primordia to develop (Fig. 2F). When they are present, the second whorl organs range in phenotype from morphologically normal stamens to staminoid petals. Third whorl organs are normal, and occupy the same positions as in wild type when all six are present. When fewer than six are formed some may be in ectopic positions. The nectaries are normal, as is the gynoecium. The phenotype of ap2-1/ap2-9 heterozygotes (Tables $2-4$ ) is slightly closer to wild type than that of ap2-1/ap2-2 heterozygotes. Fig. 3 illustrates the ap 2 allelic series, as a summary of the very broad range of phenotypes that result from the different mutant alleles at this locus.

\section{pistillata and apetala3}

Mutants homozygous for one allele each of these two unlinked loci have been described before (Bowman et al. 1989; Hill and Lord, 1989). Homozygotes for pi-1. have a normal first whorl of four sepals but the organs of the second whorl develop as sepals rather than petals. The cells that would in wild type form the organs of the third whorl appear to be largely incorporated into the gynoeclum, which is, as a consequence, abnormal in size and irregular in structure. The gynoecium usually has more than two carpels and often there are thin, filamentous structures partly or fully fused to its sides (Bowman et al. 1989; Hill and Lord, 1989). Homozygotes for ap3-1, when raised at $25^{\circ} \mathrm{C}$, have the same second whorl abnormality seen in pi-1, but the six third whorl organs are usually carpels or staminoid carpels, either solitary or connate with other members of the same whorl (Table 5). At $29^{\circ} \mathrm{C}$ the third whorl organs in ap3-1 flowers can also be free filamentous structures which are thinner than the filaments associated with wild-type stamens but usually thicker than the filamentous structures of pi-1 flowers (see Fig. 7D of Bowman et al. 1989). The two new alleles of pistillata, pi-2 and $p l-$ 3 (Table 1) have phenotypes intermediate between those of ap3-1 and pi-1, with the allelic series (in order of increasing departure from wild-type organ number and gynoecial morphology) $p i-3$, then $p i-2$, then $p i-1$. None of these $p i$ alleles is temperature sensitive.

$$
\text { pi-2 }
$$

Flowers homozygous for pi-2 (Fig. 2G) have a normal first whorl of sepals, and like $p l-1$ homozygotes, have four additional sepals in the positions normally occupied by petals in wild type. The six third whorl organ positions may be occupied by filamentous structures, by carpelloid organs, or organs may be absent (Table 5). The filamentous structures, which may be capped with stigmatic papillae, are thinner than the filaments associated with wild-type stamens but usually thicker than those observed in $p l-1$ flowers. The third whorl organs present are often congenitally fused to the central gynoecium, producing an irregular gynoecial morphology (Fig. 2G, second and third panels). In other cases, the gynoecium is normal. 


\section{pi-3}

Homozygotes for $p l-3$ are very similar to ap 3-1 mutants. They have second whorl sepals and, in the third whorl positions, either solitary carpels, staminoid carpels, or filamentous structures such as those described for pi-2 flowers (Table 5). The lateral third whorl organs are more staminoid than those occupying medial positions, and the extent of carpellody in all third whorl positions increases with the age of the inflorescence (as in ap3-1).

\section{pi-1/pi-2}

Heterozygotes of genotype $p l-1 / p i-2$ (Fig. 1E) are intermediate between the two homozygous types in third whorl organ identity. Many (33\%) of these organs are fused to the central gynoecium, regardless of their Identity A summary of the changes in organ identity in the third whorl, with increasing departure of the $p i$ phenotype from normal, is staminoid carpel, carpel, filamentous structure; with fusion to the fourth whorl organs also increasing with increasing departure from wild type (Table 5).

In all $p l$ mutants, the nectaries are normal and occupy their wild-type positions (see Smyth et al. 1990). When (as in pi-1 and some pi-2 positions) there is no third whorl organ, the nectaries are still present between the sepals occupying the second whorl and the gynoecium. The presence of nectaries thus does not depend on the development of stamens or any third whorl organ. In all pi mutants, and in ap3-1 mutants, the sepals in the second whorl are smaller than the sepals occupying the first whorl, and they develop on a relatively delayed time course, as do petals relative to sepals in wild-type flowers (Bowman et al 1989; Hill and Lord, 1989).

\section{Doubly mutant strains}

Many of our current conclusions about the domains of action of the various homeotic gene products, and about their interactions, come from study of the phenotypes of strains homozygous for different pairs of the homeotic mutations. We have previously described the phenotypes of the doubly mutant strains ag-1 pi-1; ag-1 ap3-1; ag-1 ap2-1; ap2-1 ap3-1; and ap2-1 pi-1 (Bowman et al. 1989). The alleles of $a g$ and $p i$ used in these studies display the most extreme phenotypes of those so far observed in their respective allelic series; they may thus represent null or close to null phenotypes. In contrast, the allele of $a p 2$ used, ap2-1, is the weakest allele in the series of mutations known at this locus. Consequently, we have constructed more doubly mutant strains, using the allele at the ap2 locus that shows the greatest departure from wild type, $a p 2-2$. We have also constructed an ap2-1 pi-2 strain, to observe the effect of using a weaker $p i$ allele in one combination. In addition, we present here new information on flower development in the doubly mutant strains whose mature phenotypes were previously described (Bowman et al. 1989).

$$
\text { ap2-1 pi-1, ap2-1 pi-2, and ap2-1 ap3-1 }
$$

Flowers homozygous both for $a p 2-1$ and $p i-1$ have a first whorl of four slightly carpelloid leaves (as observed in ap2-1 alone, but with a slightly increased degree of carpellody). The second whorl contains 1 to 4 organs that range from cauline leaf to solitary carpel, with most mixtures of the cell types characteristic of these organs, and none showing staminody. Third whorl organs are absent, as in pl-1 alone, and the gynoecium resembles that of pi-1 flowers (Bowman et al. 1989). When a weaker $p i$ mutant is used, such as in ap2-1 pi-2, flowers exhibit a phenotype more similar to that of ap2-1 ap3-1 flowers (Bowman et al. 1989) than to that of ap2-1 pi-1. The outer whorl is occupied by cauline leaf-like organs that can have stigmatic tissue at their tips. Second whorl organs range in phenotype from cauline leaf-like organs to organs that have characteristics of leaves, stamens and carpels. The third whorl organs are solitary carpels or filamentous structures such as those described for the third whorl of pi-2 flowers.

In each of the genotypes, both the second and third whorl organs are frequently absent. When all the positions in a whorl are occupied by an organ, the organs occupy the correct positions. When one or more are missing, however, the remaining ones develop from organ primordia that are often enlarged and occur in ectopic positions (Fig. 4A,B). In contrast, when second whorl organs are absent from ap2-1 flowers, the positions of the remaining organs are not altered and second whorl organs are never absent in ap3-1, pl-1, or $p i-2$ flowers. The development of the gynoecial cylinder is often abnormal, resulting in an unfused ovary that may also be adnate with both second and third whorl organs. The fusion between second and third whorl organs and the central gynoecium is congenital. Observations on developing flowers show that missing organs result from failure of organ primordium formation (Fig. 4A,B).

\section{ap2-2 pi-1}

When a plant is homozygous for both the strong alleles, ap2-2 and pi-1, many organs are absent (Fig. 5A). The lateral first whorl positions may be occupied by cauline leaf-like organs (11 out of 66 positions scored), carpelloid leaves, $(9 / 66)$, or filamentous structures $(22 / 66)$. In 24 of 66 positions, no organ was observed. The filamentous structures observed are either filamentous leaf-like structures or thinner squamule-like structures, such as those described in the lateral first whorl positions of ap2-2 flowers. An example of a squamule-like structure is shown in the fourth panel of Fig. 4C. The remainder of the ap 2-2 pi-1 flower consists only of a central gynoecium, which usually consists of four carpels ( 30 out of 33 flowers analyzed; Fig. 4 C). In the first five or so flowers produced on any inflorescence, the carpels in the medial positions have stellate trichomes on their abaxial surfaces, while the lateral carpels are bare (Fig. 5A). Small domes of cells may be present between the positions of the lateral outer whorl organs (or the positions where they would be expected to be, were they present) and the central ovary. These are apparently nectaries, since they arise late in development, when the gynoecium develops its stigma- 

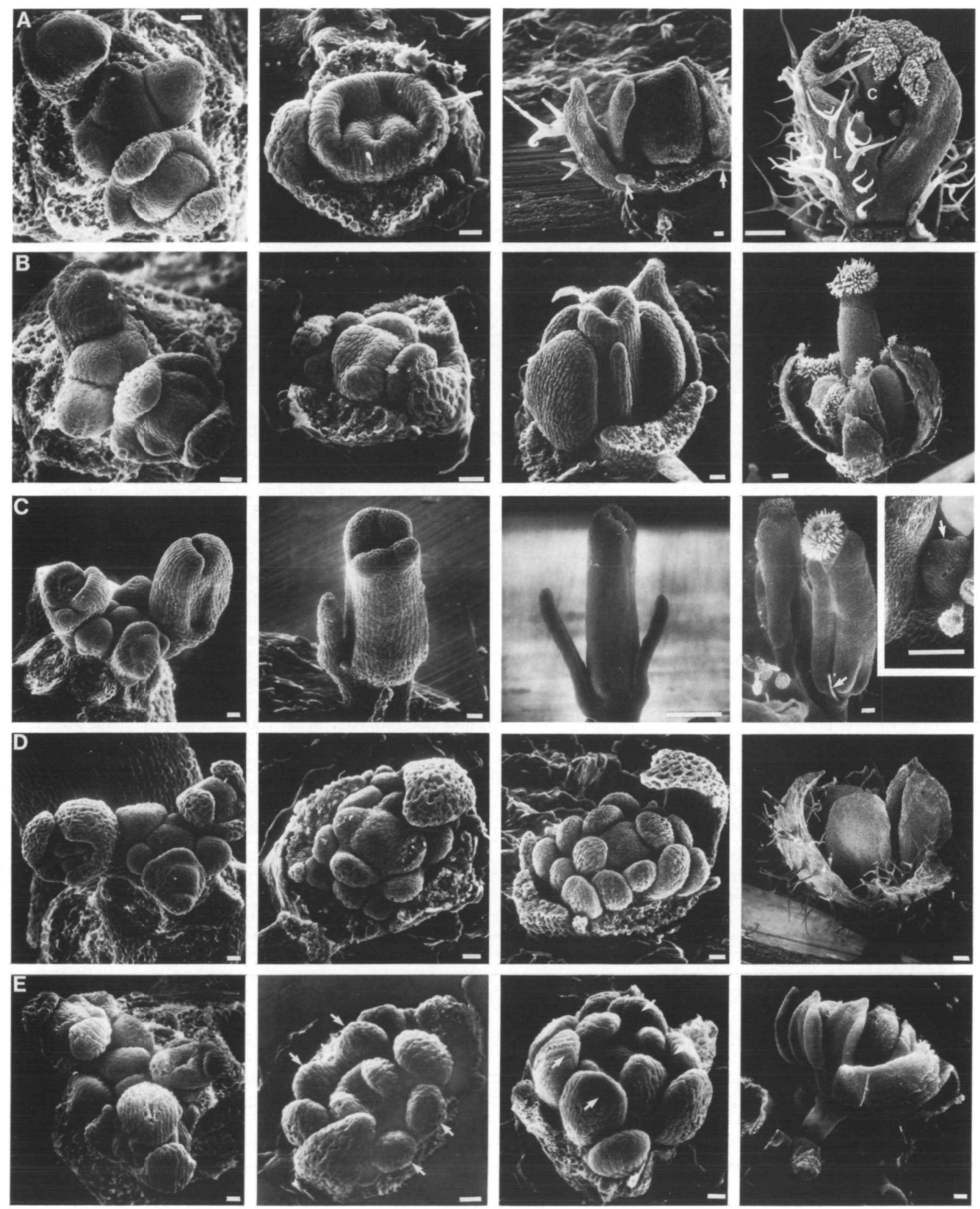
Fig. 4. Scanning electron micrographs of apetala2 double mutant combinations. The developmental series displayed in the four panels are the same format as those described for Fig. 2. All plants grown at $25^{\circ} \mathrm{C}$. Bar $=10 \mu \mathrm{m}$ in the first three panels (except the third panel of $\mathrm{C}=50 \mu \mathrm{m}$ ), $100 \mu \mathrm{m}$ in the fourth panel, and $100 \mu \mathrm{m}$ in the inset of the fourth panel of C. (A) apetala2-1 pistullata-1. The pattern of organ pnmordia is severely disrupted; all of the cells that would ordinarily give nse to the second and third whorl primordia can be recruited into an abnormal structure composed of both leaf $(\mathrm{L})$ and carpel $(\mathrm{C})$ tissue like that seen in the second and fourth panels. The outer whorl organs are caulıne leaf-like as evidenced by the presence of stellate trichomes and stıpules (arrows in third panel).

(B) apetala 2-1 apetala3-1. The pattern of second and third whorl organ primordia is disrupted (second panel).

(C) apetala 2-2 pustillata-1. Medial first whorl primordia are enlarged relative to wild type and the lateral first whorl organs arise lower on the flower primordium. The medial first whorl organs are fused to each other very early in development (panels one and two) to form a cylinder, and the remaining floral meristem appears to be incorporated into this gynoecial cylinder. An ovary composed of four carpels usually results, as seen in the second and fourth panels. Lateral first whorl organs may be missing (panels one and four), or they may be leaf-like organs (panels two and three), or filamentous structures (arrow in panel four) Nectaries may occur in the axils of these organs (arrow in the inset of panel four). The apical meristem is visible at the lower left of the fourth panel. (D) apetala2-1 agamous1. The positions of the organ primordia are similar to that of $a g .1$ flowers. Those primordia arising in the second and third whorls develop into staminold petals $(\mathrm{P} / \mathrm{S})$.

(E) apetala 2-2 agamous-1. The number of organs in the second and third whorls (8 in each of the flowers shown in the second and third panels) is greater than ever seen in ap2-2 flowers (Fig. 2C). These organs do not always arise in the proper positions; in both the second and the third panels, four of the organs seem to occupy the medial third whorl positions (arrows) but the other four organs are not in positions normally occupied in wild-type flowers. The organ primordia ansing from these positions develop into petalord stamens with conspicuous locules (panel four). These organs are much more stamen-like than those in the corresponding positions of ap2-1 ag-1 flowers. The medial first whorl organs are carpellord leaves with stigmatic tissue at their tips (panel four). The apical meristem is visible in the lower left of the fourth panel. The flower in panel two appears to have only two fourth whorl organs, in lateral positions, while the fourth whorl of the flower in the third panel consists of four organs.

tic papillae, and since stomata occur at the dome apices (Fig. 4C).

Observations on the development of ap2-2 pi-1 flowers show that the two medial first whorl organ primordia do form, and are enlarged relative to the size of wild-type medial first whorl primordia. These primordia are fused to each other as they develop, forming a cylinder that will later be a part of the central gynoecium (Fig. 4C). The cells central to these primordia, which in wild type would develop into the second, third and fourth whorls, appear to be recruited into the growing cylinder formed by the fused medial first whorl primordia. Thus, the mature gynoecium appears to consist of two medial (and slightly phylloid) carpels that originate in the first whorl, and two lateral fourth-whorl carpels. The absence of any organs developing from the second and third whorls is consistent with the phenotypes of the single mutant homozygotes, since ap2-2 mutants lack second whorl organs, and pi-1 mutants lack those of the third whorl. As seen in ap2-2 flowers, the lateral first whorl organs that form develop from primordia produced lower on the pedicel of the flower primordium than do first whorl organ primordia in wildtype flowers.

$$
\text { ap2-2 ap3-1 }
$$

Homozygotes for the strong ap2-2 allele and ap3-1 produce flowers that consist primarily of carpelloid organs, with occasional cauline leaf-like organs in the lateral first whorl positions. All of the carpelloid organs may be fused, such that the flower resembles that of ap2-2 pl-1 homozygotes, or the medial first whorl organs may be separate from the central gynoecium. Organs do sometimes form between the organs of the first and fourth whorls. These may be third whorl organs, as sometimes form in ap2-2, but they are carpels and not stamens (as in $a p 2-2$ ) as a result of the absence of the wild-type action of the $A P 3$ gene.

\section{ap2-1 ag-1}

Our earlier observations of ap2-1 ag-1 double homozygotes showed that the flowers retain the indeterminate growth characteristic of ag-1 homozygotes, but have additional changes in organ identity (Bowman et al. 1989). The first floral whorl contains four cauline leaves with stellate trichomes and stipules, as well as an epidermal cellular morphology typical of leaves (Fig. 4D). These organs have stigmatic tissue at their tips very infrequently in contrast to the first whorl organs of ap2-1 flowers that are often capped with stigmatic papillae. The second and third whorl organs are intermediate between petals and stamens, both at the organ level, and in the appearance of individual epidermal cells. Observations of the development of these flowers shows that all organs of the first three whorls originate from primordia that are in the positions and numbers of the similar primordia in wild type (Fig. 4D). The cells that would ordinarily develop into the gynoecium form, as in ag-1 homozygotes, an inner flower, whose organ number and positions may differ from those typical of wild-type flowers.

$$
\text { ap2-2 ag-1 }
$$

Remarkably, ap2-2 ag-1 double homozygotes (Fig. 5B) strongly resemble ap2-1 ag-1 double homozygotes: the absence of wild-type $A G$ activity eliminates many of the phenotypic differences between flowers homozygous for the different ap2 alleles. This strongly implies that these differences are due to different interactions of the products of the ap2 alleles with the wild-type $A G$ gene or its product, a model that will be developed in the Discussion.

The phenotype of the ap2-2 ag-1 double homozygotes includes lateral first whorl organs (which were present 
in 32 out of 44 positions counted) resembling either cauline leaves ( $22 / 32$ organs) or filamentous structures (10/32 organs). The filamentous structures may be etther leaf-like or squamule-like structures, such as those described for lateral first whorl positions of ap2-2 flowers. Six of the 22 phylloid organs had stigmatic tissue at their apices. The medial first whorl organs are carpelloid leaves (in contrast to the solitary carpels, with few leaf-like characteristics, found in the ap2-2 single mutant). These carpellord leaves have an epidermal cellular morphology of leaves, often develop with stipules at their bases, and frequently have stellate trichomes on their abaxial surfaces (Fig. 5B). Long epidermal cells of the type found only on the abaxial surface of sepals also are present, however, and stigmatic papillae and ovules may develop on the tips and margins, respectively.

Second whorl organs do occur in the double mutant, again in contrast to ap2-2 single homozygotes. Those second and third whorl organs that form are indistinguishable from each other and have both an overall morphology and individual epidermal morphologies intermediate between those ordinarily seen in petals and stamens (Fig. 4E). The organs have rudimentary locules in which pollen grains are produced, but they do not dehisce. It is of note that the number of second and third whorl organs that develop (7.6 on average) is closer to the wild-type number (10) than the number of these organs found in flowers homozygous for ap2-2 alone (average 0.25 ). The second and third whorl organs in the double homozygote arise in roughly the normal pattern (Fig. 4E).

The remaining floral meristem, which in wild type would give rise to the gynoecium, develops into another flower primordium, as in ag-1 flowers. The organ primordia in thıs (and subsequent) inner flowers differentiate in the same patterns as those of the outermost flower, with a whorl of carpelloid leaves surrounding two whorls of stamen-petal intermediate organs. Organs that resemble carpelloid leaves (in whorls $1,4,7$, etc.) may have longitudinal stamen-petal hybrid sectors along their margins, similar in pattern to the hybrid organs observed in the analogous positions in ag-1 flowers.

The ag-1 mutation thus suppresses both the extreme carpellody observed in the first whorl organs of ap2-2 flowers, and also suppresses the loss of second and third whorl organs characteristic of ap2-2 flowers. The fact that the ag-1 mutation exhibits phenotypic effects in the first and second whorls in a background homozygous for ap2-2, but shows no effects in these whorls when alone, suggests that the $A G$ and $A P 2$ genes interact at some level.

ag-1 pi-1 and ag-1 ap3-1

Finally, we will consider two other doubly mutant combinations involving agamous. Both ag-1 pi-1 and ag-1 ap 3-1 flowers consist of an indeterminate number of whorls of sepals (Bowman et al. 1989; Fig. 5C,D). The developmental basis of the phenotypes in the two different genotypes is somewhat different; ag-1 pi-1 homozygotes consist of a repeating pattern of two whorls, whereas ag-1 ap3-1 flowers have a repeating pattern of three whorls. An ag-1 pl-1 double homozygote is shown in Fig. 6A. The four outer whorl and four second whorl organ primordia are initiated in the correct positions and all of these primordia develop into sepals. The four second whorl primordia are small and develop much more slowly than the outer whorl sepals, with the result that the second whorl of sepals remains smaller than the outer whorl sepals. The cells that would normally give rise to the third and fourth whorl organ primordia behave as if they were another flower primordium, developing four organ primordia on the margins of the remaining dome of meristematic cells. This process repeats indeterminately, as seen in ag-1 flowers, thus producing a flower with many whorls, all of which have four sepals. ag-1 ap3-1 flowers also consist of an indeterminate number of sepals (Fig. 5D but, in contrast to ag-1 pi-1 flowers, the pattern of organ primordia formation is indistinguishable from that observed in ag-1 (Fig. 6B), thus consisting of repeats of three whorls, with four organs in each of the outer two whorls, then six organs in the third. Each of the organs in both ag-1 pi-1 and ag-1 ap3-1 flowers consist of cell types characteristic of wild-type sepals, complete with long epidermal cells on their abaxial surfaces.

\section{Triply mutant strains}

To extend our genetic analysis of the Arabidopsis homeotic genes, we have constructed four different strains, each homozygous for mutant alleles of three of the four homeotic loci. We will first discuss three of these strains together, since their phenotypes are similar. These strains involve ap2-1 and ag-1 in combination with ap3-1, pi-1, or pi-2.

$$
\begin{aligned}
& \text { ap2-1 ag-1 pi-1, ap2-1 ag-1 ap3-1, and ap2-1 ag-1 } \\
& \text { pi-2 }
\end{aligned}
$$

Each of these strains produce flowers that exhibit the indeterminate growth caused by the ag mutation and, in addition, all of the organs of the flower resemble cauline leaves (Fig. 7A,B). The organs are cauline leaflike in several aspects: they have stellate trichomes on their abaxial and, less frequently, on their adaxial surfaces, stipules are present at the base of most of the organs (Fig. 8A,B), they have an epidermal cellular morphology characteristic of leaves, and they senesce on the time course characteristic of leaves, not that typical of sepals (which begin to senesce soon after anthesis). They do, however, have the long epidermal cells on their abaxial surface that are characteristic of wild-type sepals.

Occasionally (in about $5 \%$ of the flowers) in each triply mutant genotype a secondary flower is formed in the axil of a lateral first whorl organ. These flowers have their own pedicel and the same phenotype as the flower in which they arise. This phenomena has also been observed in ap2-1, ap2-1 ap3-1, ap2-1 ag-1, and ap2-1 $p t-1$ flowers at a lower frequency, and occurs in almost every flower with the ap $1-1$ genotype (McKelvie, 1962; Irish and Sussex, 1990). 

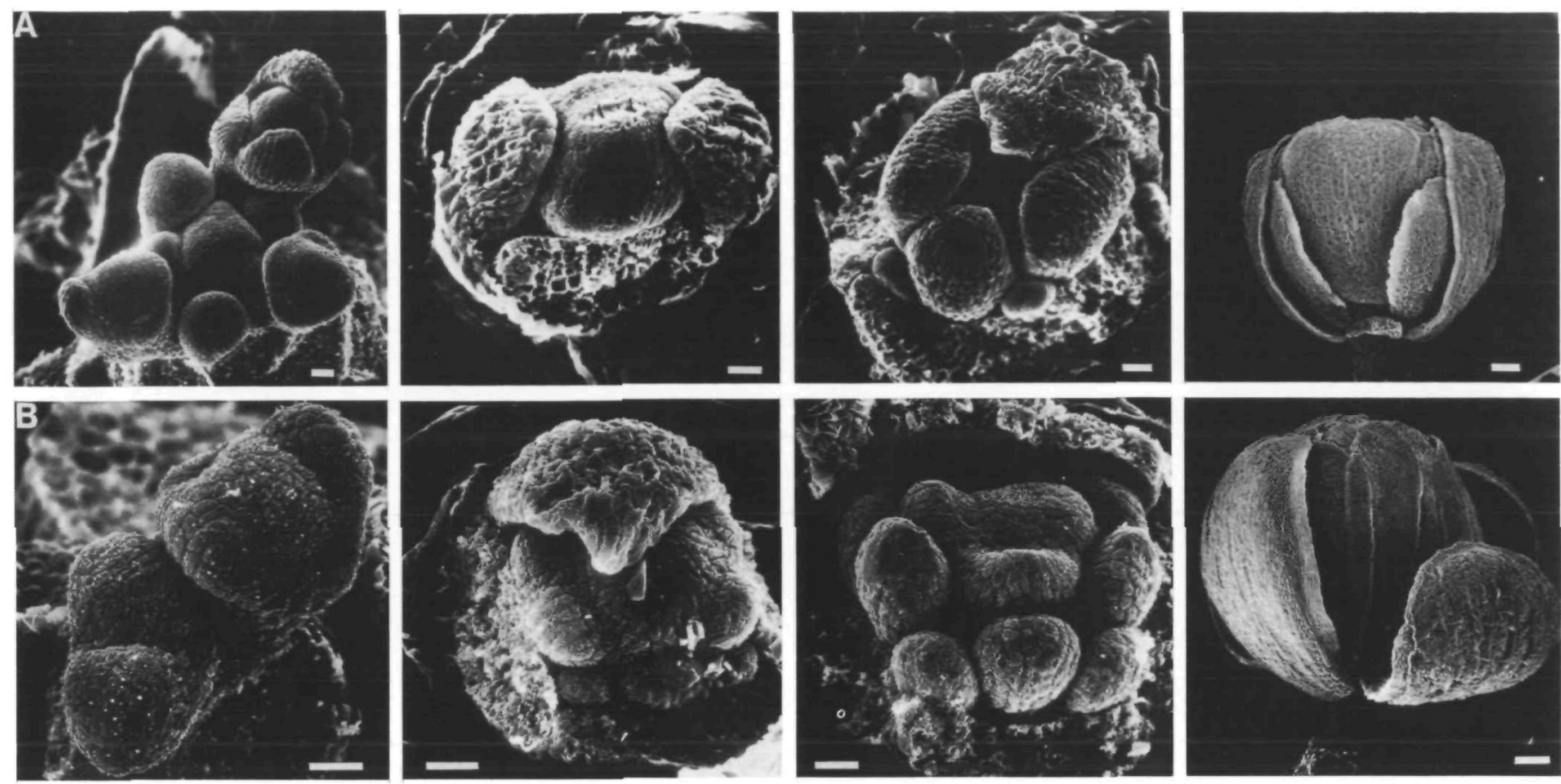

Fig. 6. Development of agamous-1 pistillata-1 and agamous-1 apetala3-1 flowers. The developmental senes displayed are the same format as those described for Fig. 2 ag-1 pl-1 plants were grown at $25^{\circ} \mathrm{C}$ while the ag-1 ap $3-1$ plants were grown at $20^{\circ} \mathrm{C}$. Bar $=10 \mu \mathrm{m}$ in the first three panels and $100 \mu \mathrm{m}$ in the fourth panel. (A) ag- $1 \mathrm{pl}-1$ After proper formation of the first two whorls of organ primordia, the third whorl organ prımordia fail to form (as observed in pl-1 flowers) and the remainıng floral meristem behaves as if it is another flower primordıum, as seen in the third panel. This process repeats indeterminately producing a flower with multiple whorls of sepals in alternate positions (fourth panel). (B) $a g-1$ ap 3-1.

Pattern of organ primordia is the same as that seen in ag-1 flowers (panel three) Due to the temperature sensitivity of the ap3-1 mutation, the second and thurd whorl organs are petalord sepals (panel four) at the intermediate growth temperature $\left(20^{\circ} \mathrm{C}\right)$ used.

In ap2-1 ag-1 ap3-1 flowers, outer whorl organ primordia are initiated in correct positions and the second whorl organ primordia are usually in wild-type positions and numbers (Fig. 8A). By contrast, the third whorl organ primordia are variable in number, position and size (Fig. 8A). The remaining floral meristem contınues to produce organ primordia but in an illdefined pattern. All of these organ primordia develop into cauline leaf-like organs (Fig. 7A).

In ap2-1 ag-1 pt-1 flowers, the identity of each organ is also that of leaf (Fig. 7B), but the pattern of the organs is different from that of ap2-1 ag-1 ap3-1. The pattern in which the organs appear deviates from that of wild type at stage 5 , when the second and third whorl primordia are normally formed (Fig. 8B). The pattern initially resembles that seen in $a g-1$ pi-1 flowers. The four first whorl primordia are initiated in the correct positions, as are the second whorl organ primordia in most cases. The remaining floral meristem then behaves as if it were a new flower, producing four more primordia on the margins of the remaining dome of cells. At this point, the floral meristem continues to produce organ primordia, but in no easily defined pattern.

Flowers of genotype ap2-1 ag-1 pi-2 have been analyzed at the resolution of light microscopy. At this level, they appear similar to the flowers of the ap2-1 ag1 ap3-1 strain.

\section{ap2-2 ag-1 pi-1}

The final genotype constructed, ap2-2 ag-1 pl-1, involved the strongest mutant alleles thus far isolated. Flowers on these triple homozygotes are composed of an indeterminate number of slightly carpelloid leaf-like organs (Fig. 7C) similar to those observed in the medial first whorl positions of ap2-2 ag-1 flowers. Each of the organs has an overall morphology intermediate between cauline leaves and carpels. The epidermal cellular morphology is characterized by irregularly shaped cells interspersed frequently with stomata, which is a phylloid appearance, though the abaxial surface also has many of the very long cells that are normally characteristic of sepals. Stellate trichomes, again a leaf character, may form on the abaxial surfaces, with their frequency decreasing on the inner organs. The most cauline leaf-like organs, which usually develop in what appears to be the lateral first whorl positions, sometimes have stipules at their bases. Stigmatic papillae develop at the tıps of most organs, and ovules may develop along the margins of the organs from what resembles placental tissue.

Development is altered as early as stage 3, when the 

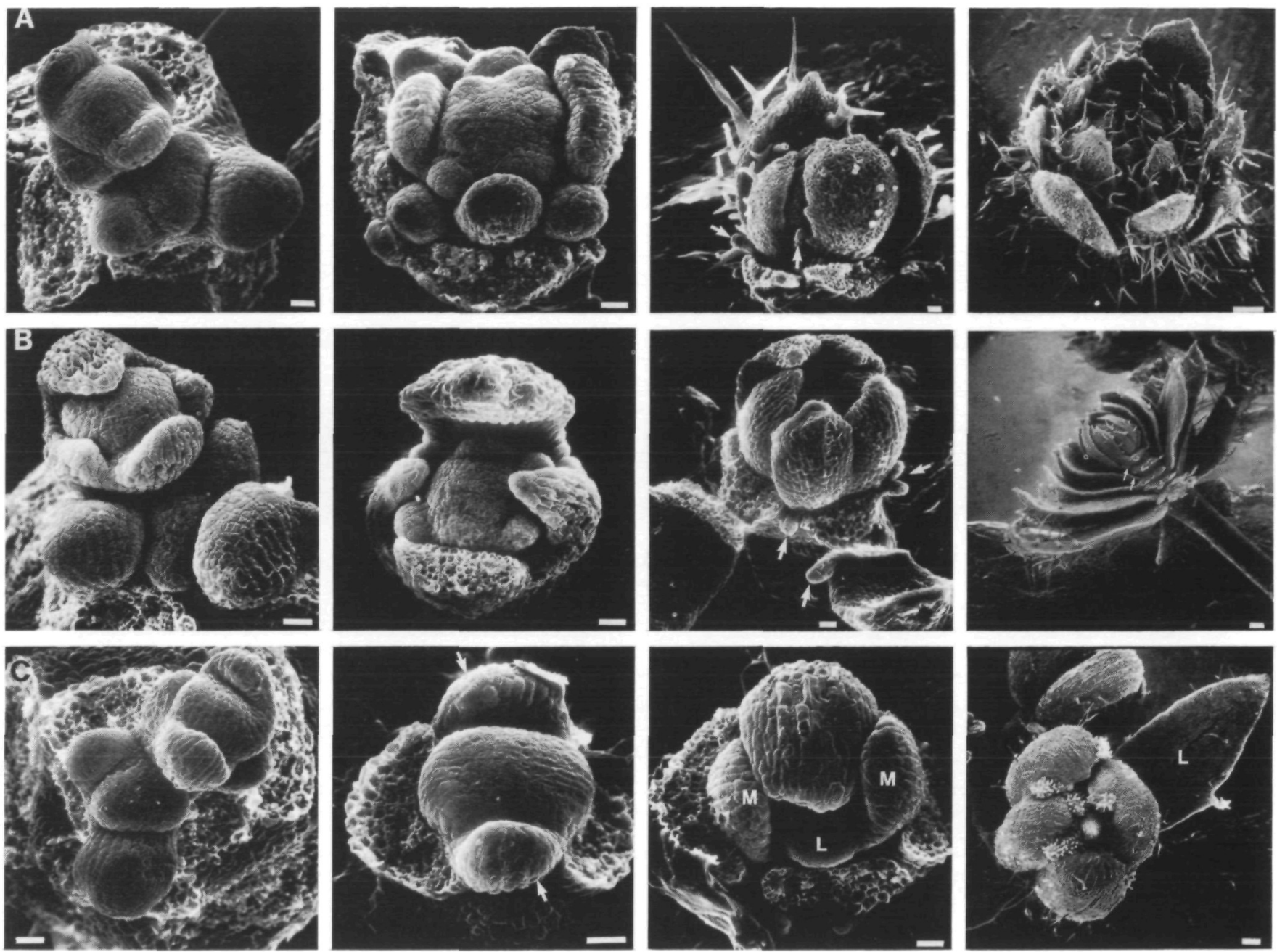

Fig. 8. Development of triply mutant flowers. The developmental series displayed for each genotype is the same format as that described in Fig. 2. All plants were grown at $25^{\circ} \mathrm{C}$. Bar $=10 \mu \mathrm{m}$ in the first three panels and $100 \mu \mathrm{m}$ in the fourth panel. (A) apetala 2-1 agamous-1 apetala3-1 Second and third whorl organ primordia may form in abnormal positions and sometımes appear to be fused, as seen in the second panel Each develops into a caulıne leaf-like organ with stellate trichomes on its abaxial surface and stıpules at its base (arrows in third panel). Developing stıpules can also be seen in the third panel. (B) apetala2-1 agamous-1 pistllata-1. The pattern of organ pnmordıa is similar to that seen in ag-1 pl-1 flowers. Stipules can be seen at the base of both the outer whorl organs in panel three and at the base of organs in the inner whorls in panel four (arrows) (C) apetala2-2 agamous-1 pistlllata-1. A flower with two medial and two lower lateral first whorl primordia can be seen in the first panel The second panel shows a flower from the lateral view, two medial first whorl organs have been removed to expose the two lateral primordia (arrows) arising interior to the first whorl. A lateral view of a slightly older flower is shown in the third panel, two medial first whorl organs have been removed as well as a lateral organ intenor to the first whorl. Two additıonal medial organ primordia (M) and another lateral organ primordia (L) interior to all the previously produced pnmordıa are visıble The fourth panel displays a mature flower with one lateral first whorl leaf-lıke organ (L), and all of the remaining organs carpellord leaves

first whorl organ primordia appear (Fig. 8C). In ap2-2 ag-1 pt-1 flowers, the medial first whorl organ primordia appear in the correct positions, but their growth is abnormal, and they differentiate into carpelloid leaves. The lateral first whorl primordia sometımes fail to form (they are present only in $11 / 18$ positions analyzed) and when they do form they appear to arise lower on the flower primordium than the position of the analogous organs in wild-type flowers. These lateral primordia differentiate either into cauline leaf-like organs with few carpelloid features ( $7 / 11$ organs), or into filamen- tous structures (4/11 organs) like those described for lateral first whorl positions of ap2-2 flowers. The remaining floral meristem produces two more organ primordia in lateral positions, directly insıde the lateral first whorl organs when these are present, and interior to all of the first whorl organs (Fig. 8C). This is followed by the production of two additional primordia in medial positions, interior to all of the previously produced primordıa. This pattern of pairs of lateral, then medial organ primordium formation repeats indefinitely, and eventually each of the primordia develops into a 
whorl: $\quad \begin{array}{llll}1 & 2 & 3 & 4\end{array}$

field:

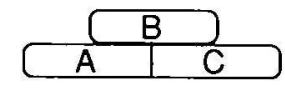

wild type
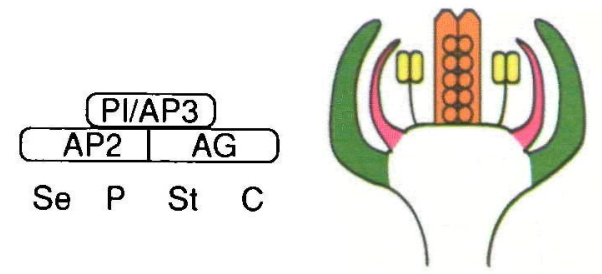

ap3 or pi

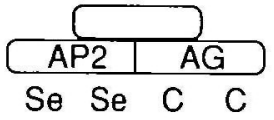

ap2

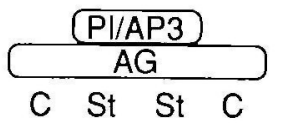

ag

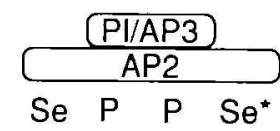

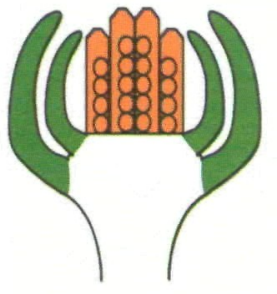

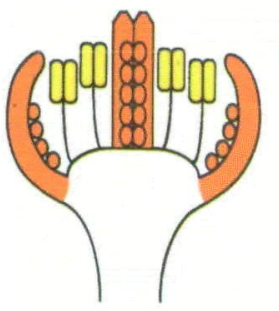

ap2 ag
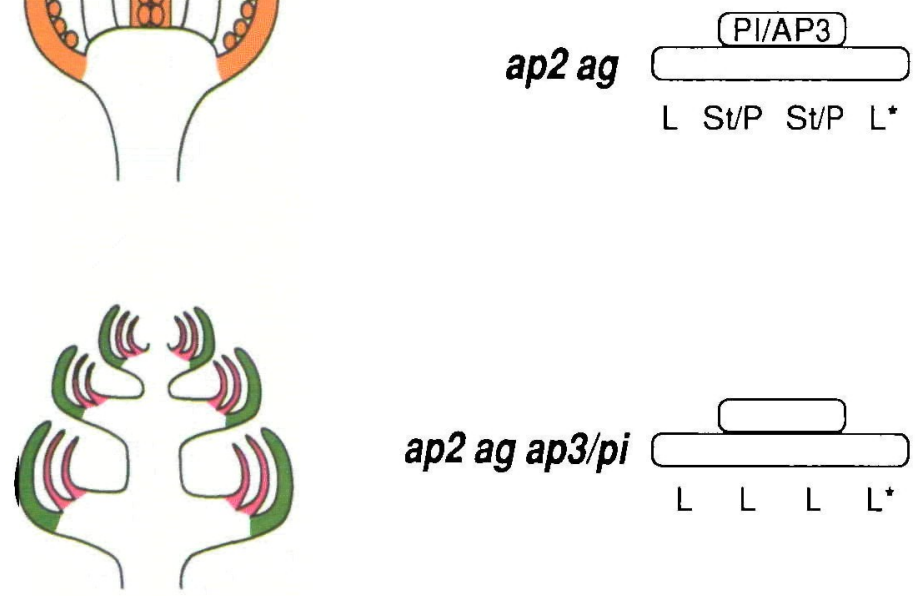

ag ap3/pi

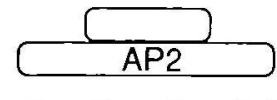

Se Se Se Se*

ap2 ag ap3/pi

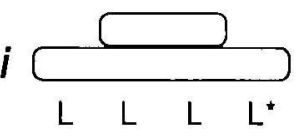

whorl: $1 \quad 2 \quad 3 \quad 4$
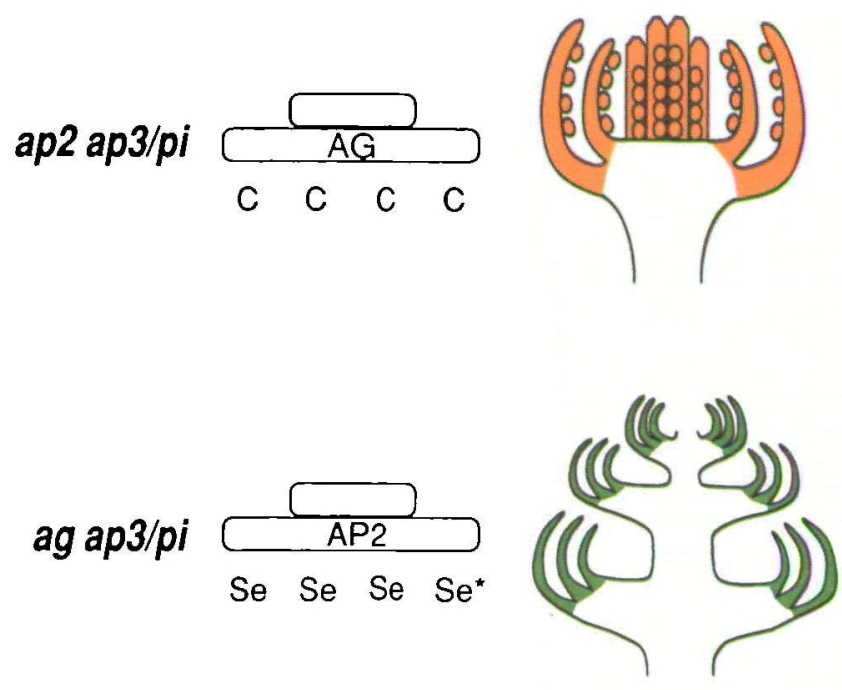

Fig. 9. A schematic representation of the model depicting how three classes of floral homeotic genes could specify the identity of each of the four whorls of floral organs A section through one-half of a floral primordium is represented as a set of boxes, with the regions representing each whorl shown at the top of each column. Each box represents a single field (defined in the Discussion); these are also shown at the top of the first column. The genotype under consideration is listed at the left with the predicted distribution of gene products present in each genotype indicated by uppercase letters within the boxes. The predicted phenotype of the organs in each whorl are shown under the diagrams. $\mathrm{Se}=\operatorname{sepal,~} \mathrm{P}=\mathrm{petal}$, $\mathrm{St}=$ stamen, $\mathrm{C}=$ carpel. $\mathrm{P} / \mathrm{St}=$ petalold stamen, an organ, present in ap 2 ag flowers, with characteristics of both petals and stamens $\mathrm{L}=$ leaf or carpelloid leaf, either can be found in the positions indicated depending upon the allele of ap2 present. The * is a reminder that in each genotype containing ag, there are several whorls of organs interior to the fourth whorl. A schematic drawing of a longitudinal cross section of each genotype of flower is depicted on the right. Each of the organ types is color coded sepals=green, petals=pink, stamens=yellow, carpels=orange, petaloid stamens $=$ gold, and leaves and carpelloid leaves=blue. The whorls interior to whorl nine in the ag containing genotypes are not shown 
Table 6. Summary of phenotypes of Arabidopsis flowers

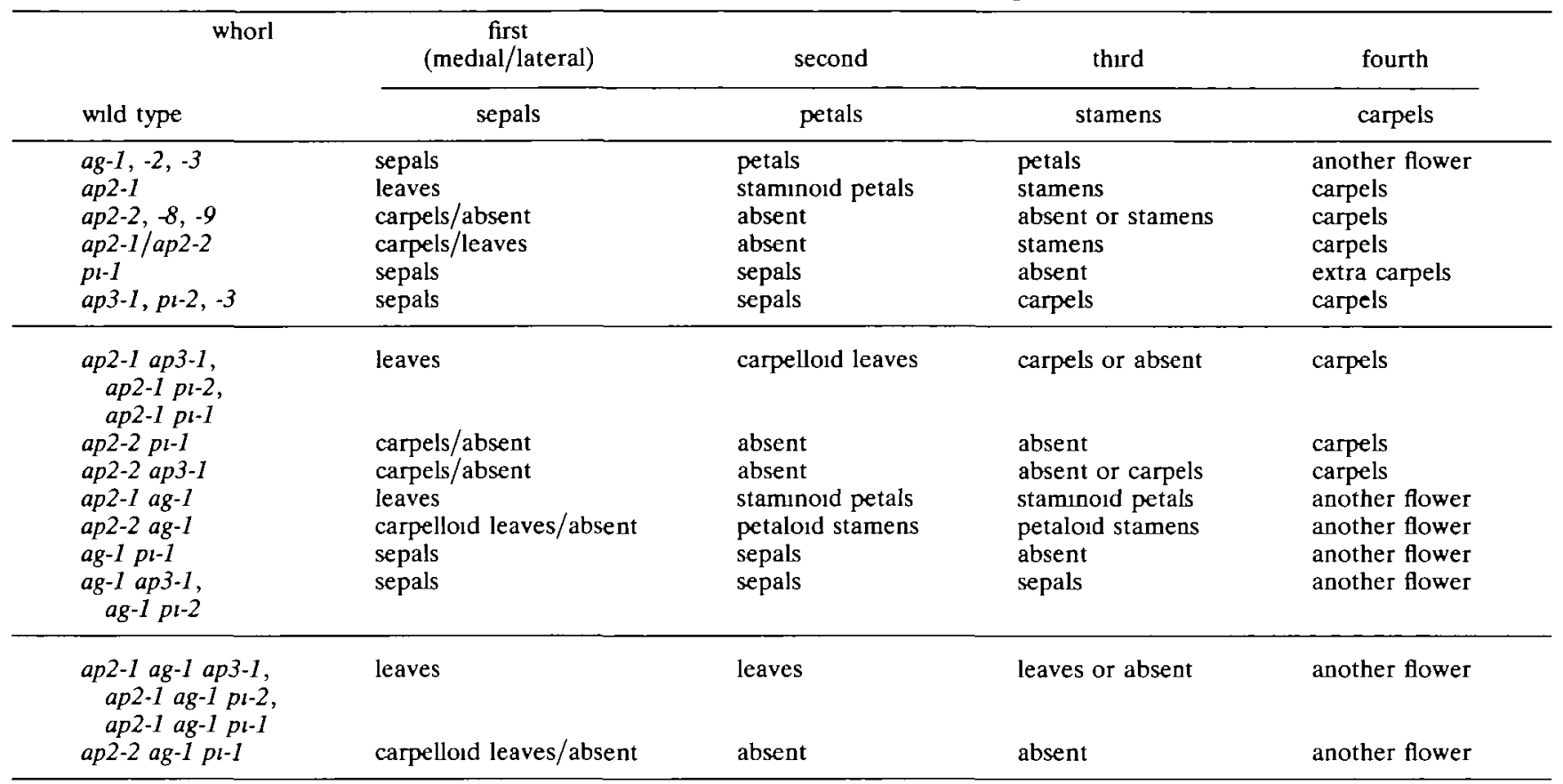

carpelloid leaf. Occasionally, the medial first whorl organs and the next two inner organs are congenitally fused, forming a ring of organs. The lateral first whorl organs have not been observed to fuse with any other organs.

The phenotypes of each of the singly, doubly and triply mutant flowers are summarized in Table 6 .

\section{Discussion}

Each of the genes, $A G, A P 2, A P 3$, and $P I$, seems to act by allowing cells to determine their positions within the developing flower, and thus to act in allowing the cells to differentiate (or to direct their progeny to differentiate) appropriately. In addition, the $A P 2, A G$ and $P I$ products appear to be involved in the initial production of floral organ primordia, which precedes their differentiation. Mutations in these genes thus result in both the misinterpretation of positional information, causing organ primordia to differentiate improperly, and the disruption of floral organ number and pattern. We have derived a model, presented below, which explains how these four genes could specify the identity of the floral organs. The model has been successful in predicting the phenotypes of doubly and triply mutant flowers, and in predicting the pattern of expression of one homeotic gene that we have cloned and analyzed so far ( $A G$, Yanofsky et al. 1990). The model does not, however, address the issue of how these and other genes act to specify the position and number of organs in the developing flower. The model is also insufficient to explain all of the organ identity phenotypes seen. It is clear, then, that what follows is an overly simple, firstorder model, which will require considerable modifi- cation as new mutations, and new phenomena, are described.

\section{A simple model}

The model is depicted in Fig. 9. The Arabidopsis wildtype flower consists of four concentric whorls of organs, arranged in a stereotypic pattern in terms of number and position. Each of the four mutations affects the differentiation of two adjacent whorls of organs, and thus falls into one of three classes: those affecting the first and second whorls, those affecting the second and third whorls, and those affecting the third and fourth whorls. The flower primordium can, consequently, be divided into concentric fields made up of pairs of adjacent whorls. The term 'field' is introduced here to refer to pairs of adjacent whorls, since these pairs of whorls, rather than single whorls, appear to be the domains of action of each of the classes of homeotic genes described. Field A is made up of whorls 1 and 2, and is the domain of action of AP2, the product of the $A P 2$ gene. Whorls 2 and 3 constitute field $\mathrm{B}$, which is the domain of AP3 and PI; and field C is made of whorls 3 and 4, the domain of AG action. AP3 and PI are grouped together for the remaining discussion because a mutation in either one results in a similar phenotype with respect to organ differentiation, and because the double mutant phenotype is indistinguishable from the single mutant phenotypes (Bowman et al. 1989). In what follows, it is important to recognize that by 'whorl' we mean a geographic location, within which organs of any identity can arise, and not the group of organs themselves. Whorls are thus identified by their position in the developing flower, and by the number and disposition of the organs within them, but not by the 
1dentity of these organs (see Bowman et al. 1989 for a longer discussion of this point).

Underlying our model is the assumption that the combination of homeotic gene products present in each whorl is responsible for specifying the developmental fates of the organ primordia that form in that whorl. The three overlapping fields of gene action thus specify each of the four different whorls of organs in the flower: in any whorl in which AP2 alone is active, sepals form. If both AP3 and PI are also present in combination with AP2, as in the wild-type second whorl, any organ primordia that are present differentiate into petals. Similarly, if $\mathrm{AG}$ alone is present, it directs any primordia in that whorl to develop into carpels, as is the case for the wild-type fourth whorl. If AP3 and PI are present in combination with AG, stamens are specified, as in the wild-type third whorl.

The final aspect of this simple model is that the $A P 2$ and $A G$ products are mutually antagonistic, such that $A G$ prevents the action of AP2 in the third and fourth whorls of a wild-type flower, and AP2 prevents the action of $A G$ in the first and second whorls. This proposal is based on observations that the ag-1 mutation has phenotypic effects in the first and second whorls in an ap 2-2 mutant background, while no first or second whorl effects are seen in ag-1 singly-mutant flowers. In ap2-2 ag flowers the first whorl develops as carpelloid leaves rather than carpels as in ap2-2 flowers, and second whorl organs, which are missing in ap2-2 flowers, are partially restored in the double mutant and have a phenotype different from that observed in any ap 2 allele alone. Likewise, the ap 2 mutations have third and fourth whorl homeotic effects when combined with ag-1, but not when alone; ap2-2 ag-1 flowers have third whorl organs intermediate between petals and stamens, while ag-1 alone has normal petals in the third whorl. If the first whorl of the inner flower in an ag mutant is considered equivalent to a wild-type fourth whorl, ap22 also has a fourth whorl effect in an ag background, namely, conversion of these fourth whorl sepals into leaves or carpelloid leaves. According to this part of the model, then, if the $A P 2$ product is missing, the phenotypic expression of $\mathrm{AG}$ expands into field $\mathrm{A}$ (whorls 1 and 2) and conversely, if the $A G$ product is absent, the phenotypic expression of AP2 expands to include field $C$ (whorls 3 and 4).

If one or more of the homeotic gene products is missing, the distribution of remaining products determines organ identity. For example, if either the $A P 3$ or $P I$ gene product is missing, leaving only those products specifying fields $\mathrm{A}$ and $\mathrm{C}$, then the outer two whorls should develop into sepals and the inner two whorls into carpels. This is indeed the case in ap3-1, and pi-3. If the $A P 2$ product is missing, $\mathrm{AG}$ is active in both fields $\mathrm{A}$ and $C$. The first and fourth whorl organs should then be carpels, and the second and third whorl organs, which develop in the presence of AG and AP3/PI, should be stamens. This is observed in the ap2 allelic series; all those organs arising from cells that would normally give rise to second and third whorl organs are staminord, whereas those arising from cells normally forming first and fourth whorl organs are carpellord. Conversely, if the $A G$ product is missing, the $A P 2$ product should be active in both fields $A$ and $C$ (with, as in wild-type, AP3/PI active in field B), and a flower in which the first and fourth whorl organs are sepals, and the second and third whorl organs are petals should (and does) develop.

\section{Predictıons for double and triple mutants}

The model makes clear predictions for the phenotypes of doubly and triply mutant flowers. For example, in $a p 3 a p 2$ and pi ap2 flowers, the $A G$ product (and none of the others) should be present in all four whorls, since the $A P 2$ product is not present to repress the activity of $A G$ in the outer two whorls. Therefore, the flowers are expected to consist entirely of carpels. This is the case in such doubly mutant flowers (Figs 4C, 5A). A similar argument can be made to predict flowers composed entirely of sepals for $a g$ p $\iota$ and $a g$ ap 3 double mutants, and this prediction is confirmed by the phenotypes of these flowers (Figs 5C,D; Bowman et al. 1989).

The prediction for ag ap2 flowers is more difficult to make, because if both the $A G$ and $A P 2$ products are absent, only the $A P 3 / P I$ products remain in field $\mathrm{B}$. This is a distribution of homeotic gene products that does not match that thought to be found in any whorl of wild-type flowers. In wild type, the formation of both petals and stamens is dependent on the $A P 3 / P I$ products. The decision as to whether to produce either a petal or a stamen, however, is dependent on the presence of either the $A P 2$ product or the $A G$ product, respectively. Thus the second and third whorl organs might be expected to have characteristics of both petals and stamens, but to be neither wild-type petals nor wild-type stamens. This is what is observed in ap2-2 ag1 flowers (Fig. 4E). The phenotype of first and fourth whorl organs in the ap2-2 ag double mutants is also difficult to predict, since whorls 1 and 4 are predicted to have none of the homeotic gene products present in them, a situation with no precedent in the wild-type flower. Thus, the organs occupying these positions should not be of a type normally found in flowers. Indeed, the organs of these whorls in ap2-2 ag-1 flowers have characteristics of leaves (Fig. 5B).

It is tempting to speculate that the known three homeotic pathways are sufficient to specify floral organs and that, in their absence, only vegetative organs can form. The developmental ground state, however, appears not to be entirely vegetative, since the organs in the first and fourth whorls of ap2-2 ag-1 flowers are carpelloid leaves. If these organs indeed exhibit the developmental ground state, all floral organs should be carpelloid leaves in the triple mutant, in which all three of the homeotic pathways are blocked. This prediction is also confirmed; all organs in ap2-2 ag-1 $p_{l-1}$ are carpelloid leaves (Figs 7C, 8C).

Each of these genes appears to control the specification of organ identity by regulating genes that are involved in the production of cellular and morphological characteristics of the different organ types, and not by directly specifying the final differentiation products. 
This is clear from the fact that organ types removed by single mutations may be partly restored by additional mutations. For example, ag mutants have no stamens, but in ap2 ag doubly mutant strains, the second and third whorl organs are in many respects staminoid. Another example is that single ag mutants have no carpellord structures, but such structures are found in the ap2-2 ag-1 pi-1 triply mutant strain.

\section{ap2-1: a special case}

The phenotypes of ap2-1 flowers seem to refute the organ specification model: the first whorl of ap2-1 flowers is composed of leaves with few carpel characteristics, not the carpels predicted by the model. This apparent exception could be explained by proposing that in the ap2-1 allele, only one of the two proposed functions of AP2 has been significantly affected. According to our model, AP2 has two functions: one is to prevent $A G$ from acting in the outer two whorls (field A), and the other is to affect directly the expression of the genes that lead to the differentiated phenotypes of sepals and petals. If the ap2-1 gene product fails to activate downstream genes, yet still prevents activity of $A G$ in whorl 1 , none of the three classes of homeotic genes would be active in whorl 1 . The model would therefore predict the development of carpellord leaves in these positions; this is what is observed in ap2-1 flowers grown at $29^{\circ} \mathrm{C}$ (Bowman et al. 1989).

First whorl positions in ap2-1 flowers grown at temperatures below $25^{\circ} \mathrm{C}$, however, are occupied by leaves with little or no carpel characteristics. In addition, in first and fourth whorl positions in ap2-1 ag1 double mutants, and in all whorls in ap2-1-containing triple mutant strains, leaves are found where carpelloid leaves are expected. The activity of AG is clearly reduced (or possibly absent) in the double and triple mutant flowers. Since the phenotype of the first whorl organs of ap2-1 flowers is nearly identical with that of the organs of the double and triple mutant flowers, the activity of AG must also be reduced in ap2-1 flowers. This implies a third function for the $A P 2$ product, to repress an as yet-unknown homeotic activity sımılar to that of $A G$, which when expressed in leaves adds some carpel characteristics. Greater loss of AP2 function, as in ap 2-2, allows this activity to function, thus producing carpelloid leaves, while a low level of AP2 activity, as in ap2-1, represses it (variably) and results in leaves with few or no carpel characteristics. Quadruple mutants for the unidentified gene and all three of the known homeotic paths would have true leaves in all floral organ positions, and this collection of gene classes would be sufficient for specifying all of the differences between vegetative and floral organs.

This proposal predicts either that the $A P 2$ product has two or more separable domains of function, or that different levels of the $A P 2$ product are required for its different functions. The staminord petals in the second whorl of ap2- 1 flowers are unlike those in the second and third whorls of ap2-2 ag- 1 flowers (they consist of sectors of stamen tissue, sectors of petal tissue, and sectors that appear intermediate between petal and stamen tissue, Pruitt et al. 1987; Bowman et al. 1989). This implies variable repression of $A G$ in the second whorl in ap2-1, and a variable ability of the $A P 2$ product in this whorl to affect downstream genes. In the stamen tissue, the $A P 2$ product appears not to accomplish either of its functions; in the petal tissue, it performs both of its functions; and in the hybrid sectors, it is repressing $A G$, but is not contributing to the differentiation process.

\section{Unexplained complications \\ Mosaic organs and whorls}

As stated previously, the proposed model does not address questions of how the homeotic genes affect organ number and organ position. Beyond this shortcoming, there are other observations relatıng to organ identity, which is within the realm of our model, that are not incorporated.

The presence of phenotypically mosarc organs in a number of the genotypes examined presents one aspect not readily explained by the model. Prominent examples are organs consisting of carpel and stamen sectors in the first whorl positions of ap2-2, ap2-8 and ap2-9 flowers. These ap2 alleles alter the number, size and shape of all four whorls of organ primordia, as well as the pattern of differentiation of the organs in the outer two whorls. The first whorl organ primordia from which the mosaic organs develop appear to be larger, and to involve a greater proportion of the flower primordium, than do the first whorl organ primordia in wild-type flowers (Fig. 2C,D). It could be that these organ primordia are large enough to encompass more than a single geographic whorl within the developing flower. The shape of these primordia is such that their margins could arise from cells that would normally be part of the second or third whorls while the central parts of the primordia arise from cells of the outer whorl. This would explain why the stamen sectors are always on the margins, and the carpel sectors always occupy the central portion of the phenotypically mosaic organs. A similar argument may be made for the phenotypically mosaic (mixed sepal and petal) inner whorl organs in ag-1, -2 and -3 flowers. This would suggest that the formation of fields specifying differentiation of cell types, and hence organ types, is to some degree independent of the formation of organ primordia.

The importance of organ primordium position within the developing flower is emphasized by the different fates of the medial and lateral first whorl organ primordia. As noted in this and in other studies (Komaki et al. 1988; Kunst et al. 1989) of ap2, the medial first whorl organs are generally carpelloid, while the lateral first whorl organs are quite leaf-like, even in the stronger alleles. In wild-type flowers, the lateral primordia are only slightly lower on the pedicel than the medial first whorl primordia (Smyth et al. 1990). By contrast, in ap2 flowers the lateral first whorl organ primordia are initiated much lower on the pedicel than the medial first whorl primordia. If the activity of the genes that specify floral organ identity is not present in 
the lower cells, which would normally give rise to the receptacle and pedicel, organ primordia arising ectopically from these cells might be expected to differentiate, inappropriately, into leaf-like organs.

\section{Secondary flowers}

Another observation that does not immediately fit with the model is that of secondary flowers that develop in the axils of the lateral first whorl organs of singly, doubly and triply mutant flowers with the ap2-1 genotype. The lateral first whorl organs in ap2-1 resemble cauline leaves. They have stellate trichomes on their abaxial surfaces, leaf-like epidermal and internal cellular morphologies, and stipules at their base. These are all characteristics of leaves and not of floral organs. Another characteristic of Arabidopsis leaves, both radical (rosette) and cauline, is that each has an associated meristem in its axil. Thus, it may not be surprising that organs that have the identity of leaves develop meristems in their axils. For genuine radical and cauline leaves, the meristem is an inflorescence meristem. In $a p 2-1$ floral leaf-like organs, it is a floral meristem, indicating the possibility that meristem identity, like organ identity, can be determıned independently of position.

\section{Second whorl leaves}

A final detail not easily explained by the model is the occurrence of leaf-like organs in the second whorl of ap2-1 flowers grown at $16^{\circ} \mathrm{C}$ (Bowman et al. 1989). Regardless of the activity of the product of the ap2-1 allele, it is expected that the presence of wild-type PI and AP3 activities in this field B position would modify the leaf fate of these organs. It apparently does not, at least in some instances.

\section{Interpretation of the ag fourth whorl and the problem of indeterminacy}

The cells that would ordinarily give rise to the fourth whorl gynoecium in wild-type flowers form another flower in ag. The fourth whorl of organs in ag flowers may thus be interpreted as either a fourth whorl of sepals, replacing the fourth whorl carpels of wild-type flowers (the explanation used above), or as the first whorl of sepals in an internal flower. The number and positions of the organs support the second interpretation, while the identity is, in either case, consistent with our model. Therefore, the structure of ag flowers is most easily described as a reiterated pattern: (first whorl, second whorl, third whorl $)_{n}$ with no fourth whorl organs ever forming. Likewise, the structures of ag- $1 \mathrm{pi}$ 1 flowers and ap2-2 ag-1 pi-1 flowers could be described as the reiterated patterns of organs: (first whorl, second whorl $)_{n}$ and (medial first whorl) $n_{n}$, respectively. This interpretation does not affect the organ differentiation model presented, except to show that we may not know what the phenotype of $A P 2$ expression in a fourth whorl organ might be.

The larger question of the nature of action of the wild-type $A G$ product in suppressing indeterminate growth of the floral meristem is left unanswered. It seems that this activity could partially explain the absent organs in whorls 1 and 2 in ap2 mutants: the absence of AP.2 activity in these whorls allows AG to act in them, which could then suppress cell division during their development. This is consistent with the observation that removal of the $A G$ product from these ap 2 whorls (in the ap2-2 ag- 1 double mutants) partially restores organ number toward wild-type. The number of second and third whorl primordia in ap2-2 ag-1 flowers (average number of 7.6) is closer to the wildtype number (10) than the number found in flowers homozygous for ap2-2 alone (average 0.25).

\section{Missing organs in mutant flowers result from the fallure to initiate organ primordia}

In several $a p 2$ and $p i$ alleles, organs fail to develop. For example, second and third whorl organs may be missing in ap2-2, ap2-8 and ap2-9 flowers, and second whorl organs are often absent in ap2-1/ap2-2 flowers and ap21 flowers grown at $29^{\circ} \mathrm{C}$ (Bowman et al. 1989). In each of these instances, as well as in the $p i$ alleles, there is no evidence of organ primordia at any stage of development in those positions lacking organs (Fig. 2C-F). Previous descriptions of the ap2-6 and ap2-7 alleles, however, (Kunst et al. 1989) suggested that second whorl organ primordia of flowers homozygous for these alleles form in wild-type positions and numbers, but fail to develop properly (ap2-7) or fuse to the first whorl organs (ap2-6). However, the outgrowths of cells described as second whorl organ primordia in ap2-6 and ap 2-7 flowers may not be organ primordia, but rather stipules (due to the phylloid character of the outer whorl organs; see Fig. 11B of Kunst et al. 1989) or squamules, small filamentous outgrowths of cells that have been documented in other species of Brassicaceae (see Figs 5A,B and 11C,D of Kunst et al. 1989; Arber, 1931; Smyth et al. 1990) and ap1-1 flowers (Irish and Sussex, 1990; D.R.S. and J.L.B. unpublished). Stipules arise early in development (stage 3-4 for first whorl organs) while squamules arise much later. Further analysis of developing ap2-6 and ap2-7 flowers should clarify this uncertainty.

\section{Predicted spatial and temporal expression patterns}

If the homeotic genes act autonomously, certain predictions can be made about their expression patterns. AP2 should be expressed in the outer two whorls and as early as stage two, prior to the appearance of the first whorl primordia (Bowman et al. 1989). Likewise, $A G$ expression could be restricted to the inner two whorls. The expression of either $A P 3$ or $P I$ or both should be localized in the middle two whorls. $A P 3$ should be expressed as early as stage five and should continue at least through stage seven and possibly much later (Bowman et al. 1989). The lack of third whorl primordia in pi-1 flowers suggests that its expression should start prior to stage five, the time at which the third whorl primordia arise. An important prediction is that the expression pattern of $A G$ should expand to include all four whorls in an ap2 background and conversely the expression of $A P 2$ should be in all 
whorls in an ag background. It should be noted that what is meant by expression is not restricted to the level of transcription since translational or post-translational control are plausible options. In addition, only one of the products needs be restncted to achieve the phenotypic results if one of the products is functionally inactive in the presence of the other

One of these genes, $A G$, has been recently cloned and encodes a putative transcription factor (Yanofsky et al. 1990). mRNA tissue in situ hybridization shows that its expression in wild-type plants is localized to whorls three and four (Yanofsky et al. 1990; Gary N. Drews, J.L.B., and E.M.M., submitted for publication). Furthermore, in an ap2-2 mutant background, the range of expression expands to include all whorls, supporting the hypothesis that AP2 negatively regulates $A G$ in the outer whorls in the developing flower (G. N. Drews, J.L.B., and E.M.M., submitted for publication). Another flower homeotic gene, deficiens, which when mutated results in a phenotype similar to those of ap3 and pi, has been cloned from Antirrhinum (Sommer et al. 1990). This gene is predominantly expressed in petals and stamens although a low level of expression has been reported to occur in sepals and carpels (Schwarz-Sommer et al. 1990).

The timing of initial $A G$ and $A P 2$ expression could play a role in their localization. Tissue in situs to mRNA show that $A G$ expression is not detectable until stage three, when the first whorl organ primordia become morphologically distinct from the remainder of the developing flower. In contrast, the tsp of the ap2-1 allele encompasses stages two through four, prior to and during the formation of the first whorl primordia, suggesting that the initial expression of $A P 2$ precedes that of $A G$. Since the formation of the four whorls of floral organ primordia is a sequential process, it is lıkely that the expression patterns of the genes responsible for pattern formation in the developing flower are influenced by this sequential nature. For example, $A P 2$ could initially be expressed in cells that will give rise to the outer two whorls of organs prior to and during the time of their formation. This would preclude the expression of $A G$ in these whorls. $A P 2$ expression would then be curtalled in the remaining floral meristem due to either loss of positive regulation by some factor that was responsible for its expression in the outer two whorls or negative regulation by a newly expressed factor, such as AG. In this case, $A G$ would be expressed in those cells that will give rise to the thurd and fourth whorl organs precluding $A P 2$ expression in the inner two whorls. The spatial regulation of AP3 and PI could be attained by having their expression commence only after the first whorl is formed and having a gene such as SUPERMAN (Bowman and Meyerowitz, 1991; Meyerowitz et al. 1991) negatively regulate their expression in the fourth whorl. Thus, mutations in $A P 2$ would be expected to have the most dramatic effects since it is one of the first genes expressed in sequential but overlapping gene pathways specifying both cellular identities and organ primordium patterns.
A candidate for a gene responsible for the regulation of the homeotic genes is leafy (Haughn and Sommerville, 1988; Detlef Weigel, John Alvarez, and D.R.S., unpublished). When this locus is mutated, the floral meristem behaves as if it were an inflorescence meristem. Each floral menstem produces a number of cauline leaf-like organs in a phyllotactic spiral; the later ones produced are often carpelloid. This phenotype is similar to that of the triple mutant ap2-2 pi-1 ag-1 flowers in which all organs are carpelloid leaves but, in the case of the triple mutant strain, the organs are arranged in a radial phyllotaxy. Other genes must be involved as well, to produce the complex patterns of expression expected of the later-acting homeotic genes, and the change in phyllotaxy from spiral to whorled.

\section{Evolutionary considerations}

Finally it should be noted that mutations similar to those described here exist in many other species of plants. For example, the agamous phenotype, which is commonly referred to as a double flower, has been described in Matthiola (Dodoens, 1568: see Saunders, 1921), Cheiranthus (Masters, 1869), Petunia (Sink, 1973) and Antirrhinum (Carpenter and Coen, 1990; Schwarz-Sommer et al. 1990) as well as many others (see Penzig 1890-4; Meyer, 1966; Reynolds and Tampion, 1983; Meyerowitz et al. 1989; for reviews). ap2 homologues have been reported in Capsella (Dahlgren, 1919; Shull, 1929) and Antirrhinum (Carpenter and Coen, 1990; Schwarz-Sommer et al. 1990) and ap3/pi homologues have been described in Cheiranthus (Sirks, 1924; Nelson, 1929) and Prtmula (Brieger, 1935) in addition to Antirrhinum (Stubbe, 1966; Sommer et al. 1990; Carpenter and Coen, 1990). That numerous mutants homologous to those described here occur in other plant families suggests that the mechanisms governıng flower development in $\mathrm{Arabl}$ dopsis are likely to operate in many flowering plants. When genetic experiments simular to those reported here have been done with other species, direct comparisons of the actions and interactions of homeotic genes in these species will be possible, and an assessment can be made of the degree to which these mutations are homologous with those of Arabidopsis.

We thank our colleagues, Laura Brockman, Caren Chang, Gary Drews, Bruce Hamilton, Tom Jack, Leslie Sieburth, Alex van der Bliek and Detlef Weigel for insightful discussions and critıcal review; Ken Feldmann for providing the ag.2 allele; and Pat Coen of the Electron Microscope Facility at Caltech for technical advice. This study was assisted by Natıonal Science Foundation grant DCB-8703439 to E.M.M. J.L.B. is partially supported by trainıng grant 5T32GM07616 of the National Institutes of Health.

\section{References}

ArBer, A (1931) Studies on floral morphology II On some normal and abnormal crucifers With a discussion on teratology and atavism New Phytol 30, 172-203

Bowman, J. L and Meyerowitz, E M (1991) Genetic control of pattern formation dunng flower development in Arabıdopsis thaluana. In Molecular Btology of Plant Development, Symp 
Soc exp Bıol XXXXIV (ed G I Jenkıns and W Schuch), The Company of Bıologists Ltd , Cambridge U.K , (In press) Bowman, J L., Smyth, D R and Meyerowitz, E M (1989) Genes directing flower development in Arabidopsis. The Plant Cell 1, 37-52.

Bowman, J L., Yanofsky, M F and Meyerowttz, E. M (1988) Arabidopsis thaliana A review. Oxford Surv Plant molec cell Bıol 5, 57-87

Brieger, F G. (1935). The developmental mechanics of normal and abnormal flowers in Primula Proc. Linn Soc Lond. 147, $126-130$

Carpenter, R and COEN, E S (1990) Floral homeotic mutations produced by transposon-mutagenesis in Antrrhinum majus. Genes Dev 4, 1483-1493.

DAHLGREN, K. V. O. (1919) Erblichkettsversuche mit einer dekandrischen Capsella bursa pastorns (L.) Svensk Bot Tidsknft $13,48-60$

Dodoens, R (1568) Florum, et Coronartarum Odoratarumque Nonnullarum Herbarum Histona p 21 Antwerp: C. Plantun

Haughn, G. W. and Somerville, C R. (1988) Genetic control of morphogenesis in Arabidopsis Dev Genet 9, 73-89

HiLl, J P AND LoRd, E M (1989). Floral development in Arabidopsis thaluana. Companson of the wildtype and the homeotic pustillata mutant Can J Bot 67, 2922-2936

IRISH, V F AND Sussex, I. M (1990) Function of the apetalal Gene during Arabidopsis Floral Developemnt The Plant Cell 2, 741-753

Komaki, M K , OKada, K , Nishino, E and Shimura, Y. (1988). Isolation and characterization of novel mutants of Arabudopsis thaltana defective in flower development. Development 104, 195-203

Kunst, L , Klenz, J E , Martinez-Zapater, J and Haughn, G W (1989). AP2 gene determines the identity of penanth organs in flowers of Arabudopsus thaluana. The Plant Cell 1, 1195-1208.

Masters, M T (1869) Vegetable Teratology An Account of the Principle Deviations from the Usual Construction of Plants London Ray Society

McKelvie, A. D (1962) A list of mutant genes in Arabidopsis thaliana (L) Heynh Radiatıon Bıology 1, 233-241

Meyer, V. G. (1966) Flower abnormalities. Bot Rev 32, 165-195

MEYEROWITZ, E M (1987) ArabidopsLs thallana. A Rev Genet 21, 93-111

Meyerowitz, E. M., Bowman, J L , Brockman, L L., Drews, G. N , Jack, T., Sieburth, L E. ANd Weigel, D (1991) A genetic and molecular model for flower development in Arabıdopsts thalıana Development 1991 Supplement 1 (John
Innes Conference on the Molecular and Basis of Pattern Formation), in press

Meyerowitz, E M , Smyth, D R and Bowman, J L (1989) Abnormal flowers and pattern formation in floral development Development 106, 209-217

MÚller, A. (1961) Zur Charakterisıerung der Blüten und Infloreszenzen von Arabidopsis thaliana (L) Heynh Kulturpflanze 9, 364-393.

NeLSON, A (1929) The inhentance of sex in an abnormal (carpellodic) wall-flower Proc $R$ Soc Tasmania 1928, 119-122

Penzig, O (1890-4) Pflanzen-Teratologie Systematisch geordnet, vol $1(1890)$ and 2 (1894) A Cimınago, Genua

Pruitt, R E, Chang, C, Pang, P P - Y and Meyerowitz, E M (1987) Molecular genetics and development of Arabidopsts In Genetic Regulation of Development, 45th Symp Soc dev Biol (ed W Loomis), pp 327-338 New York: Liss

ReYnolds, J. And Tampion, J. (1983) Double Flowers, $A$ Scientfic Study New York Van Nostrand Reinhold

Saunders, E R (1921) Note on the evolution of the double stock (Matthiola incana) $J$ Genet. 11, 69-74

Schwarz-Sommer, Z, HuJuser, P, Nacken, W, Saedler, H and SOMmer, H. (1990) Genetic control of flower develoment. homeotic genes in Antrrhinum majus Sclence 250, 931-936

SHULL, G. H (1929) Species hybridization among old and new species of shepherd's purse. Int Congr Plant Sct 1, 837-888.

SINK, K. C (1973) The inhentance of apetalous flower type in Petunia hybrida Vllm and linkage tests with the genes for flower doubleness and grandiflora characters and its use in hybrid seed production. Euphyaca 22, 520-526

SIRKS, M J. (1924). Die gynanthere Form des Goldlacks und thre Vererbung Genetica 6, 537-547

Smyth, D. R., Bowman, J. L. ANd Meyerowttz, E M (1990) Early flower development in Arabidopsis The Plant Cell 2, 755-767.

Sommer, H., Beltran, J. P., Huijser, P., Pape, H., Lonnig, W.E, SaEdler, H and Schwarz-Sommer, Z (1990) Defictens, a homeotic gene involved in the control of flower morphogenesis in Antrrhinum majus the protein shows homology to transcription factors. EMBO J 9, 605-613

Stubbe, H. (1966) Genetik und Zytologle von Antırrhınum L sect. Antırrhinum, VEB Gustav Fischer Verlag, Jena.

Yanofsky, M F, MA, H , Bowman, J L, Drews, G N , Feldmann, K A and Meyerowtrz, E M (1990) Resemblance of the protein encoded by the Arabidopsis homeotic gene agamous to transcnption factors Nature 346, 35-39

(Accepted 14 January 1991) 